Estimation of Freely-Dissolved Concentrations of Polychlorinated Biphenyls, 2,3,7,8-Substituted Congeners and Homologs of Polychlorinated Dibenzo-p-dioxins and Dibenzofurans in Water for Development of Total Maximum Daily Loadings for the Bluestone River Watershed, Virginia and West Virginia

Open-File Report 07-1272 

Estimation of Freely-Dissolved

Concentrations of Polychlorinated

Biphenyls, 2,3,7,8-Substituted Congeners

and Homologs of Polychlorinated Dibenzo-

p-dioxins and Dibenzofurans in Water

for Development of Total Maximum

Daily Loadings for the Bluestone River

Watershed, Virginia and West Virginia

By Robert W. Gale

Open-File Report 2007-1272 


\section{U.S. Department of the Interior DIRK KEMPTHORNE, Secretary}

\section{U.S. Geological Survey \\ Mark D. Myers, Director}

\section{U.S. Geological Survey, Reston, Virginia: 2007}

For product and ordering information:

World Wide Web: http://www.usgs.gov/pubprod

Telephone: 1-888-ASK-USGS

For more information on the USGS--the Federal source for science about the Earth, its natural and living resources, natural hazards, and the environment:

World Wide Web: http://www.usgs.gov

Telephone: 1-888-ASK-USGS

Any use of trade, product, or firm names is for descriptive purposes only and does not imply endorsement by the U.S. Government.

Although this report is in the public domain, permission must be secured from the individual copyright owners to reproduce any copyrighted materials contained within this report.

Suggested citation:

Gale, R.W., 2007, Estimation of freely-dissolved concentrations of polychlorinatedbiphenyls, 2,3,7,8-substituted congeners and homologs of polychlorinated dibenzo- $p$-dioxins and dibenzofurans in water for development of total maximum daily loadings for the Bluestone River watershed, Virginia and West Virginia: U.S. Geological Survey OpenFile Report 2007-1272, 27 p. 


\section{Contents}

Abstract

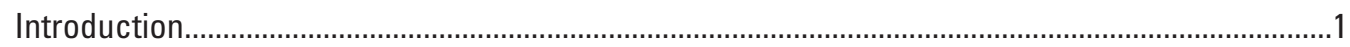

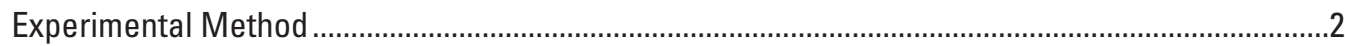

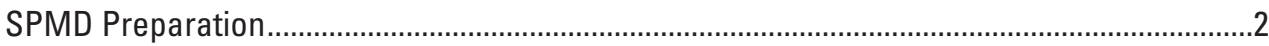

SPMD Performance Reference Compounds (PRCs) ………..............................................

Native PCB and PCDD/DF Fortification .........................................................................

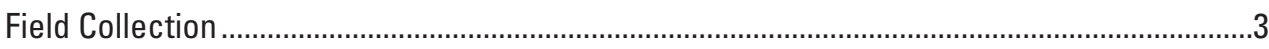

Initial Sample Processing...........................................................................................

Procedural Internal Standard Fortification and Dialytic Recovery of Contaminants.......3

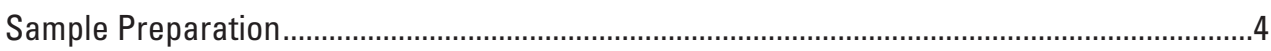

Secondary Reactive Column Cleanup ......................................................................

High Performance Size-Exclusion Chromatographic (HP-SEC) Fractionation ..................4

High Performance Porous Graphitic Carbon Chromatographic (HP-PGC)

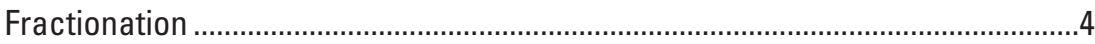

Low Pressure Basic Alumina Chromatographic (LP-BAC) Fractionation .........................4

Congener-Specific Polychlorinated Biphenyl Analysis...................................................

Polychlorinated Dibenzo-p-Dioxin and Dibenzofuran Analysis .......................................5

Secondary Sample Preparation—Additional OC Samples................................................

Confirmatory Congener-Specific Polychlorinated Biphenyl Analysis ...............................5

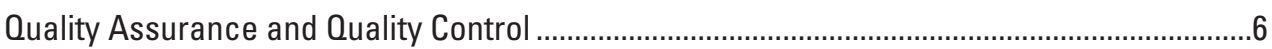

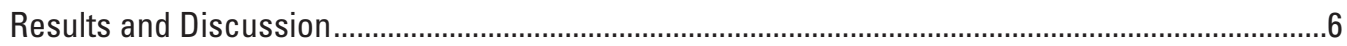

SPMD Accumulation of Selected Congeners of Polychlorinated Biphenyls ..........................6

SPMD Accumulation of 2,3,7,8-Substituted Congeners and Homologs of Polychlorinated Dibenzo- $p$-Dioxins and Dibenzofurans .......................................................................

SPMD Release of Performance Reference Compounds (PRCs) ..........................................10

Calculation of Estimated Concentrations of PCBs, PCDDs, and PCDFs in Water...................11

Concentrations of Selected Congeners of Polychlorinated Biphenyls in Water ............11

Concentrations of 2,3,7,8-Substituted Congeners and Homologs of Polychlorinated Dibenzo- $p$-Dioxins and Dibenzofurans in Water ...................................................11

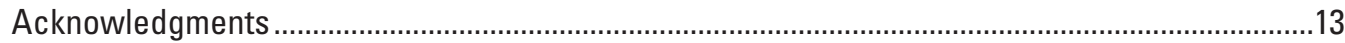

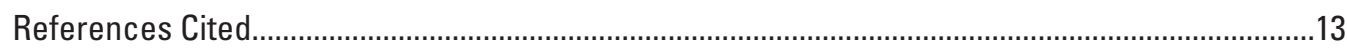

Tables 


\section{Tables}

1. SPMD samples deployed and collected from the Bluestone River watershed, Tazewell County, Virginia, and Mercer County, West Virginia (Waterbody VAS-N36/N37R) .

2. Amounts of total polychlorinated biphenyls (PCBs), total polychlorinated dibenzo- $p$-dioxins (PCDDs) and total polychlorinated dibenzofurans (PCDFs) per semipermeable membrane device (SPMD) composite sample for the Bluestone River watershed sample set, fall 2005.

3. Percentages of performance reference compounds (PRCs) remaining in semipermeable membrane device (SPMD) composite samples from the Bluestone River watershed sample set, fall 2005.

4. Average $a_{\text {OPRC }}$ intercept values of performance reference compounds (PRCs), maximum and minimum volumes of water sampled, and estimated uncertainties in sampling rates for semipermeable membrane device composite samples from the Bluestone River watershed sample set, fall 2005

5. Estimated concentrations of selected congeners of polychlorinated biphenyls (PCBs) in water from the Bluestone River watershed sample set, fall 2005.

6. Estimated total concentrations in water of polychlorinated biphenyls (PCBs), polychlorinated dibenzo- $p$-dioxins (PCDDs) and polychlorinated dibenzofurans (PCDFs) from the Bluestone River watershed sample set, fall 2005

7. Estimated concentrations of 2,3,7,8-substituted polychlorinated dibenzo-p-dioxins (PCDDs) and dibenzofurans (PCDFs), and homologs of dioxins and furans in water from the Bluestone River watershed sample set, fall 2005. 


\section{Conversion Factors and Datum}

\begin{tabular}{|c|c|c|}
\hline Multiply & By & To obtain \\
\hline \multicolumn{3}{|c|}{ Length } \\
\hline micrometer $(\mu \mathrm{m})$ & 0.00003937 & inch (in.) \\
\hline centimeter $(\mathrm{cm})$ & 0.3937 & inch (in.) \\
\hline meter $(\mathrm{m})$ & 3.281 & foot $(\mathrm{ft})$ \\
\hline \multicolumn{3}{|c|}{ Area } \\
\hline square meter $\left(\mathrm{m}^{2}\right)$ & 10.76 & square foot $\left(\mathrm{ft}^{2}\right)$ \\
\hline square centimeter $\left(\mathrm{cm}^{2}\right)$ & 0.1550 & square inch $\left(\mathrm{ft}^{2}\right)$ \\
\hline \multicolumn{3}{|c|}{ Volume } \\
\hline microliter $(\mu \mathrm{L})$ & 0.0000002642 & gallon (gal) \\
\hline milliliter (mL) & 0.0002642 & gallon (gal) \\
\hline liter $(\mathrm{L})$ & 0.2642 & gallon (gal) \\
\hline cubic meter $\left(\mathrm{m}^{3}\right)$ & 264.2 & gallon (gal) \\
\hline \multicolumn{3}{|c|}{ Flow rate } \\
\hline liter per day $\left(\mathrm{L} \cdot \mathrm{d}^{-1}\right)$ & 0.2642 & gallon per day $\left(\right.$ gal $\left.\cdot \mathrm{d}^{-1}\right)$ \\
\hline \multicolumn{3}{|c|}{ Mass } \\
\hline femtogram (fg) & $3.527 \times 10^{-17}$ & ounce, avoirdupois (oz) \\
\hline picogram (pg) & $3.527 \times 10^{-14}$ & ounce, avoirdupois (oz) \\
\hline nanogram (ng) & $3.527 \times 10^{-11}$ & ounce, avoirdupois (oz) \\
\hline microgram $(\mu \mathrm{g})$ & $3.527 \times 10^{-8}$ & ounce, avoirdupois (oz) \\
\hline milligram (mg) & $3.527 \times 10^{-5}$ & ounce, avoirdupois (oz) \\
\hline $\operatorname{gram}(\mathrm{g})$ & 0.03527 & ounce, avoirdupois (oz) \\
\hline kilogram (kg) & 2.205 & pound avoirdupois (lb) \\
\hline \multicolumn{3}{|c|}{ Density } \\
\hline gram per cubic centimeter $\left(\mathrm{g} / \mathrm{cm}^{3}\right)$ & 62.4220 & pound per cubic foot $\left(\mathrm{lb} / \mathrm{ft}^{3}\right)$ \\
\hline \multicolumn{3}{|c|}{ Concentration } \\
\hline nanogram per gram $\left(\mathrm{ng} \cdot \mathrm{g}^{-1}\right)$ & $=$ & part per billion $\left(\mathrm{ppb} ; 10^{9}\right)$ \\
\hline milligram per liter $\left(\mathrm{mg} \cdot \mathrm{L}^{-1}\right)$ & $=$ & part per million (ppm; $\left.10^{6}\right)$ \\
\hline microgram per liter $\left(\mu \mathrm{g} \cdot \mathrm{L}^{-1}\right)$ & $=$ & part per billion $\left(\mathrm{ppb} ; 10^{9}\right)$ \\
\hline nanogram per liter $\left(\mathrm{ng} \cdot \mathrm{L}^{-1}\right)$ & $=$ & part per trillion (pptr; $10^{12}$ ) \\
\hline picogram per liter $\left(\mathrm{pg} \cdot \mathrm{L}^{-1}\right)$ & $=$ & part per quadrillion (ppq; $10^{15}$ ) \\
\hline nanogram per milliliter $\left(\mathrm{ng} \cdot \mathrm{mL}^{-1}\right)$ & $=$ & part per billion $\left(\mathrm{ppb} ; 10^{9}\right)$ \\
\hline
\end{tabular}

Temperature in degrees Celsius $\left({ }^{\circ} \mathrm{C}\right)$ may be converted to degrees Fahrenheit $\left({ }^{\circ} \mathrm{F}\right)$ as follows:

$$
{ }^{\circ} \mathrm{F}=\left(1.8 \times{ }^{\circ} \mathrm{C}\right)+32
$$

Concentrations of chemical constituents in water are given in milligrams per liter $\left(\mathrm{mg} \cdot \mathrm{L}^{-1}\right)$. micrograms per liter $\left(\mu \mathrm{g} \cdot \mathrm{L}^{-1}\right)$, nanograms per liter $\left(\mathrm{ng} \cdot \mathrm{L}^{-1}\right)$, picograms per liter $\left(\mathrm{pg} \cdot \mathrm{L}^{-1}\right)$, or femtograms per liter $\left(\mathrm{fg} \cdot \mathrm{L}^{-1}\right)$. 



\title{
Estimation of Freely-Dissolved Concentrations of Polychlorinated Biphenyls, 2,3,7,8-Substituted Congeners and Homologs of Polychlorinated Dibenzo-p-dioxins and Dibenzofurans in Water for Development of Total Maximum Daily Loadings for the Bluestone River Watershed, Virginia and West Virginia
}

\author{
By Robert W. Gale
}

\begin{abstract}
The Commonwealth of Virginia Department of Environmental Quality, working closely with the State of West Virginia Department of Environmental Protection and the U.S. Environmental Protection Agency is undertaking a polychlorinated biphenyl source assessment study for the Bluestone River watershed. The study area extends from the Bluefield area of Virginia and West Virginia, targets the Bluestone River and tributaries suspected of contributing to polychlorinated biphenyl, polychlorinated dibenzo- $p$-dioxin and dibenzofuran contamination, and includes sites near confluences of Big Branch, Brush Fork, and Beaver Pond Creek.

The objectives of this study were to gather information about the concentrations, patterns, and distribution of these contaminants at specific study sites to expand current knowledge about polychlorinated biphenyl impacts and to identify potential new sources of contamination. Semipermeable membrane devices were used to integratively accumulate the dissolved fraction of the contaminants at each site. Performance reference compounds were added prior to deployment and used to determine site-specific sampling rates, enabling estimations of time-weighted average water concentrations during the deployed period.

Minimum estimated concentrations of polychlorinated biphenyl congeners in water were about 1 picogram per liter per congener, and total concentrations at study sites ranged from 130 to 18,000 picograms per liter. The lowest concentration was 130 picograms per liter, about threefold greater than total hypothetical concentrations from background levels in field blanks. Polychlorinated biphenyl concentrations in water fell into three groups of sites: low (130-350 picogram per liter); medium (640-3,500 picogram per liter; and high (11,000-18,000 picogram per liter). Concentrations at the high sites, Beacon Cave and Beaverpond Branch at the Resurgence,
\end{abstract}

were about four- to sixfold higher than concentrations estimated for the medium group of sites.

Minimum estimated concentrations of polychlorinated dibenzo-p-dioxin and dibenzofuran congeners in water were about 0.2 to 1 femtograms per liter. Estimated total concentrations of 2,3,7,8-substituted congeners in water at study sites ranged from less than 1 to 22,000 femtograms per liter and less than 1 to 2,300 femtograms per liter for polychlorinated dibenzo- $p$-dioxin and dibenzofuran congeners, respectively. Total concentrations of 2,3,7,8-substituted congeners in water were comprised largely of octachlorodibenzo- $p$-dioxin and dibenzofuran, with less than 10 percent of the total contributed by concentrations of other congeners, mainly 2,3,7,8-heptachlorodibenzo- $p$-dioxin and dibenzofuran.

Of special interest for this study was 2,3,7,8-tetrachlorodibenzo- $p$-dioxin with a regulatory surface water-quality criterion of 1,200 femtograms per liter. Estimated concentrations in water ranged from 0.5 to 41 femtograms per liter. Concentrations in water were less than 5 femtograms per liter at all study sites, except the Bluefield Westside Sewage Treatment Plan, with an estimated concentration of 41 femtograms per liter.

Estimated total concentrations of homologs of polychlorinated dibenzo- $p$-dioxins and dibenzofurans in water at the study sites ranged from 3,200 to 36,000 femtograms per liter and 210-4,800 femtograms per liter, respectively. Again, homologs of polychlorinated dibenzo- $p$-dioxins and dibenzofurans in water were comprised largely of octachlorodibenzo$p$-dioxin and dibenzofuran.

\section{Introduction}

The Commonwealth of Virginia Department of Environmental Quality (VADEQ), working closely with the State of West Virginia Department of Environmental Protection 
(WVDEP) and the U.S. Environmental Protection Agency (USEPA) is undertaking a polychlorinated biphenyl (PCB) source assessment study for the Bluestone River watershed.

This watershed is located in the coalfields of Virginia and West Virginia, where historically, over 300 mining industry related facilities existed, many of which employed PCB-containing oils. Many of these operations have [since] closed. Some facilities were located in the remote valleys and ridges of the watershed, and other, smaller facilities, were home-based operations. The goals of the proposed source assessment are to ensure that no site is actively contributing PCBs to the watershed and to provide a baseline for the PCB Total Maximum Daily Load (TMDL) study required by the Clean Water Act. In the United States, commercially used technical mixtures of PCBs are commonly referred to as Aroclors ${ }^{\circledR}$ (Mosanto, St. Louis, Mo.) with a naming convention using a four-digit number denoting, first, the ring system (12 for biphenyl) and then the average percent chlorination (for example, 42 percent) (Frame and others, 1996); PCBs are referred to as Aroclors ${ }^{\circledR}$ in many State regulations. Currently, the calculated total PCB surface water-quality criteria (SWQC), based on the weight percent of each homolog group of the technical PCBs are $1,700 \mathrm{pg} \cdot \mathrm{L}^{-1}$ and $47 \mathrm{pg} \cdot \mathrm{L}^{-1}$ for the Commonwealth of Virginia and for West Virginia, respectively (Virginia State Water Control Board, 1997; Virginia Water Quality Standards, 2006; West Virginia Environmental Quality Board, 2000).

The Bluestone River watershed study is complicated by several factors (Lott and Newman, 2005). Most PCB misuse and improper disposal occurred decades ago and over a wide area. The karst geology of the region moves water from the surface through underground pathways near known or suspected PCB contaminated sites. Because of differential loadings of PCBs, differing exposure scenarios, and different target organisms, the transport mechanisms and bioaccumulation potential for PCBs are different in each watershed and even within a sub-watershed. The watershed crosses the VirginiaWest Virginia State Line; tributaries from industrial areas in West Virginia enter Virginia and ultimately the Bluestone exits Virginia into West Virginia, thus requiring a cooperative assessment and TMDL approach to be developed by the Commonwealth of Virginia and the State of West Virginia.

Existing records of PCB related activities of State and Federal agencies and previous PCB sampling schemes, PCB environmental data, and reports of activity, cleanups, and site closures in the watershed have been compiled by the VADEQ. Potential PCB sources were identified by personal contacts and results of survey forms to gain information about historic PCB usage in the watershed; leading to locations of several contaminated sites.

The objectives of this study were to gather information about the concentrations, patterns, and distribution of selected congeners of PCBs, polychlorinated dibenzo- $p$-dioxins (PCDDs), and polychlorinated dibenzofurans (PCDFs) at specific study sites to expand current knowledge about PCB impacts and to identify potential new sources of contamina- tion. Semipermeable membrane devices (SPMDs) were used to integratively accumulate the dissolved fraction of PCBs and PCDDs/DFs at each site. Performance reference compounds were added to the SPMDs prior to deployment and used to determine site-specific sampling rates of SPMDs, enabling estimations of time-weighted average (TWA) water concentrations of PCBs and PCDDs/DFs during the deployed period. This information will be used by the VADEQ, WVDEP, and USEPA to compare TWA concentrations with the SWQC for each analyte to determine those analytes potentially exceeding the proposed TMDLs being developed for the Bluestone River watershed.

\section{Experimental Method}

\section{SPMD Preparation}

Standard SPMDs ( $1 \mathrm{~m} \times 2.5 \mathrm{~cm} \times \sim 70-80 \mu \mathrm{m}$ thickness, $1.00 \mathrm{~mL}$ 2,3-bis[[(E)-octadec-9-enoyl]oxy]propyl (E)-octadec9-enoate (triolein), each) were deployed and composited for this work. Performance reference compound (PRC) loss rates equivalent to sampling rates of $2-4 \mathrm{~L} \cdot \mathrm{d}^{-1}$ were used to predict sampling rates for this study and the compositing required to attain these detection limits. The use of six standard SPMDs per site was calculated to provide sufficient sampling, once composited, to achieve the lowest quantification limit required; approximately tenfold less than targeted quantification SWQC for 2,3,7,8-TCDD of $1.2 \mathrm{pg} \cdot \mathrm{L}^{-1}$.

Semipermeable membrane devices were prepared for the VADEQ for deployment at 15 selected sites in the Virginia portion of the Bluestone River watershed, two of these sites were replicated $(n=2)$ for a total of 17 sampling points. Three field blank SPMD composite samples, three fortified field blank SPMD composite samples, one fabrication blank SPMD composite sample, and one fortified field blank composite sample also were prepared. This required preparation and addition of PRCs to 150 standard SPMDs. Semipermeable membrane device composites also were prepared for the WVDEP for deployment at three selected sites in the West Virginia portion of the Bluestone River watershed along with three field blank samples. The number and configuration of the devices necessary to achieve the specified detection limits was the same as for VADEQ, six standard SPMDs per composite. No fortified field blank SPMD composite samples or other quality control (QC) samples were prepared for the WVDEP deployment. This required the additional preparation and addition of PRCs to 36 standard SPMDs.

\section{SPMD Performance Reference Compounds (PRCs)}

Suitable PRCs for the target analytes were selected for calibration (Huckins and others, 1999, 2002, 2006). The 
previous deployment used only perdeuterated polycyclic aromatic hydrocarbons (PAH- $d$ ) (Lott and Newman, 2005), which were not considered completely acceptable as PRCs in this study because of their potential for photolytic degradation and dissimilarity to the analytes; rather, selected PCB congeners (PCB-014, PCB-029, and PCB-050) not found at any appreciable level in commercial Aroclors ${ }^{\circledR}$ were used here. However, the perdeuterated polycyclic aromatic hydrocarbons (acenaphthylene- $d$, acenaphthene- $d$, fluorene- $d$, phenanthrene- $d$, and pyrene- $d$ ) were included here as PRCs for comparative purposes.

A volume of $200 \mathrm{~mL}$ of purified triolein was required for this sample set, allowing enough residual triolein for anticipated SPMD losses and for preparing various QC samples. The $200 \mathrm{~mL}$ triolein was fortified with a 1,000 ng of each PCB and $200 \mu \mathrm{g}$ of each PAH- $d$ by addition of isooctane solutions of the PRC-PCBs and the PRC-PAH- $d$ to triolein and removal of the residual isooctane by rotary-evaporation. The PRCPCBs were added at $5.0 \mathrm{ng} \cdot \mathrm{SPMD}^{-1}$ and the PRC-PAH- $d$ were added at $1.0 \mu \mathrm{g} \cdot \mathrm{SPMD}^{-1}$; or $30.0 \mathrm{ng}$ and $6.00 \mu \mathrm{g}$ per composite, respectively.

\section{Native PCB and PCDD/DF Fortification}

Composites of six SPMDs, representing the one fortified fabrication blank and the three fortified field blanks were fortified with a mixture of native PCBs and PCDDs/DFs at levels near the quantification limits to determine the recovery efficiencies of the overall method. The native PCBs were added as a 1:1:1:1 mixture of Aroclors ${ }^{\circledR} 1242: 1248: 1254: 1260$. Current estimates of total PCB method background concentrations (as the sum of selected congeners) are about $7.5 \mathrm{ng} \cdot \mathrm{SPMD}^{-1}$, or $45 \mathrm{ng}$ per composite. Therefore, 1,200 ng of Aroclor®1:1:1:1 was added, to allow quantification above potential background levels of PCBs. The PCDDs/DFs were added as a native standard solution of the tetra- through octa- chlorinated 2,3,7,8substituted congeners. There are no current estimates of PCDD/ DF method background concentrations for SPMDs; however, the 1997 Columbia River Study (McCarthy and Gale, 1999) reported levels for 2,3,7,8-tetrachlorodibenzo- $p$-dioxin (TCDD) of about 1-3 pg.SPMD ${ }^{-1}$, which would be equivalent to about 6-20 pg in procedural blanks and in field blanks. Therefore, 240 pg of 2,3,7,8-TCDD were added; and because the native PCDD/ DF standard solution contains levels of congeners that increase with degree of chlorination, the amounts of individual PCDD and PCDF congeners added were: $\mathrm{Cl}_{4}-240 \mathrm{pg} ; \mathrm{Cl}_{5-7}-1,200 \mathrm{pg}$; and $\mathrm{Cl}_{8}-2,400 \mathrm{pg}$, respectively.

\section{Field Collection}

The extent of the Bluestone River watershed to be sampled was in the Bluefield area of Virginia and West Virginia, targeting the Bluestone River and tributaries suspected of contributing to PCB and PCDD and PCDF contamination; includ- ing sites near confluences of Big Branch, Brush Fork, and Beaver Pond Creek. Fifteen deployment sites were selected by the VADEQ and three additional sites selected by the WVDEP. Site selection was based on considerations of appropriate site availability for SPMD deployment and specific stream conditions at each site. The design of the study required SPMD deployments at points where lateral mixing in the flow regime of each site was optimized, providing the most representative sampling of the stream at both high and low flow periods. The coordinates for each sampling point were documented by a geographic positioning system. Locations of these points were also described relative to existing landmarks, and all pertinent information concerning target analytes was compiled by the VADEQ as part of this study.

The deployment and collection of SPMDs for this project were accomplished by the VADEQ, WVDEP, and USGS personnel. These field personnel developed a sampling plan in accordance with USGS, VADEQ, and USEPA requirements (Standard Operating Procedures Manual, 2003; Water Quality Monitoring Consolidated Guidance, 2004). All deployed samples consisted of six standard SPMDs per site. Samples were transported to and from the site in precleaned sealed cans placed on ice. Field blanks were shipped, transported, and handled in the field in a manner consistent with the actual samples (for example, cans were opened and SPMDs were handled). All sampling equipment was cleaned prior to sampling and cleaned after each use. All samples were stored at $-20^{\circ} \mathrm{C}$ in sealed cans placed in coolers, and were handled under chain of custody. The samples were shipped overnight to the USGS Columbia Environmental Research Center, where they were logged, and stored at $-20^{\circ} \mathrm{C}$.

\section{Initial Sample Processing}

Processing of SPMD samples consisted of inspection of the devices; all observations were noted and discussed with the principal investigator. Any punctures or leaking seals were resealed and documented. The exterior surface of the each SPMD was cleaned to remove any adhering particulates and the biofilm.

\section{Procedural Internal Standard Fortification and Dialytic Recovery of Contaminants}

The Procedural Internal Standard (PIS) solution was prepared by combining stock solutions to prepare $12.00 \mathrm{~mL}$ of a fortification solution containing PCB-155 (2, ', '4, ', , 6, ', hexachlorobiphenyl) and PCB-204 (2,2',3,4,4',5,6,6'-octachlorobiphenyl) at $133 \mathrm{pg} \cdot \mu \mathrm{L}^{-1}$ and ${ }^{13} \mathrm{C} 2,3,7,8$ - substituted PCDDs/DFs at concentrations ranging from 3.33-6.67 $\mathrm{pg} \cdot \mu \mathrm{L}^{-1}$. Each SPMD in each composite sample (and in each field blank, fortified field blank, fabrication blank, and fortified fabrication blank) was opened, fortified with one-sixth $(50 \mu \mathrm{L})$ of the total specified amount of procedural internal standards, 
and resealed as was performed for the native PCB and PCDD/ DF fortification in the previous section.

After fortification with PIS or PIS and native analytes and resealing, each SPMD was individually dialyzed according to established procedures. Hexane dialysis through the low density polyethylene membrane recovers small molecular weight target analytes $(<1,000 \mathrm{Da})$ from the triolein reservoir and the membrane itself with greater than 99 percent efficiency. All dialysates from the individual SPMDs comprising one composited sample were combined, and concentrated in volume to $6.0 \mathrm{~mL}$ (1.0 SPMD-equivalents $\cdot \mathrm{mL}^{-1}$, or SPMD-eq $\left.\cdot \mathrm{mL}^{-1}\right)$.

\section{Sample Preparation}

\section{Secondary Reactive Column Cleanup}

Interfering anthropogenic and biogenic compounds in dialysates were removed by reaction in a layered sulfuric acidtreated silica gel/potassium hydroxide treated silica gel/silica gel column (SASG/KS/SG). The secondary reactive cleanup columns were calibrated for the collection of the appropriate target analyte fraction (c-PCBs/PCDDs/DFs) using a dichloromethane/hexane solvent scheme. The collected fractions were solvent-exchanged to dichloromethane and concentrated in volume to $1.00 \mathrm{~mL}$.

\section{High Performance Size-Exclusion Chromatographic (HP-SEC) Fractionation}

HP-SEC was used to separate the analytes from residual higher molecular weight compounds in the reactive cleanup fractions. Higher molecular weight compounds are only slightly retained and elute prior to most target analytes; also, any elemental sulfur, a problematic interference during analysis, is more highly retained than the analytes, and elutes after the analyte fraction is collected. The HP-SEC was calibrated for the collection of the appropriate analyte fraction (c-PCBs/ PCDDs/DFs). The reactive cleanup fractions were then fractionated by HP-SEC at the rate of six SPMD-equivalents per HP-SEC cycle. The collected HP-SEC fractions were solventexchanged to isooctane and concentrated in volume to $1.0 \mathrm{~mL}$.

\section{High Performance Porous Graphitic Carbon Chromatographic (HP-PGC) Fractionation}

Separation of the PCDDs and PCDFs from PCBs and other polyhalogenated hydrocarbons was necessary to remove potentially interfering chemicals that typically may be present at concentrations several orders of magnitude greater than those of the dioxins and furans, and to thereby achieve the required detection limits. The extended-pi systems of planar aromatic chemicals (PCDDs/DFs, and non-ortho-substituted PCBs) interact very strongly and very specifically with $p i-$ system in the graphitic planes of the porous graphitic carbon, providing a highly selective and efficient fractionation mechanism. The HP-PGC was calibrated for the collection of the appropriate analytes: (fraction 1) weakly retained monoortho - tetra-ortho-substituted PCBs (c-PCBs); (fraction 2) non-ortho-substituted PCBs (not collected); and (fraction 3) PCDDs/DFs. The collected c-PCB fractions were concentrated, solvent-exchanged to isooctane, and concentrated in volume to 6.0 SPMD-eq $\cdot \mathrm{mL}^{-1}$ for dual-column gas chromatography with electron-capture detection (GC-ECD) analysis. The collected $\mathrm{PCDD} / \mathrm{DF}$ fractions were solvent exchanged to isooctane and concentrated in volume to about $0.5 \mathrm{~mL}$ for further fractionation by low pressure basic alumina chromatography.

\section{Low Pressure Basic Alumina Chromatographic (LP-BAC) Fractionation}

Residual PCBs and other polyhalogenated hydrocarbons that potentially interfere with the high-resolution mass-spectrometric analysis for PCDDs and PCDFs were minimized by chromatographic separation of the resulting HP-PGC PCDD/ DF fractions by LP-BAC. Most polyhalogenated hydrocarbon interferences are only slightly retained and elute prior to most analytes; also, any remaining biogenic materials may be more highly retained than the analytes, and elute after the analyte fraction is collected. The LP-BAC columns were calibrated for the collection of the appropriate analyte fraction (PCDDs/DFs) using a dichloromethane/cyclohexane solvent scheme. The collected LP-BAC fractions were concentrated in volume to about $0.5 \mathrm{~mL}$.

\section{Congener-Specific Polychlorinated Biphenyl Analysis}

Instrumental internal standards (IIS) were added to each c-PCB fraction and the final volume adjusted to 6.0 SPMDeq. $\mathrm{mL}^{-1}$. Individual $\mathrm{PCB}$ congeners were measured in sample fractions by dual-column GC-ECD. Analyses were performed using cool on-column capillary injection onto retention gaps connected to a $60 \mathrm{~m} \times 0.25 \mathrm{~mm} \times 0.25-\mu \mathrm{m}$ film thickness 5 percent phenyl-, 95 percent methylsilicone capillary column, and a $60 \mathrm{~m} \times 0.25 \mathrm{~mm} \times 0.25-\mu \mathrm{m}$ film thickness 50 percent phenyl-, 50 percent methylsilicone capillary column, respectively. Potential peaks for PCB congeners were matched and identified on one or both GC capillary columns with individual congener standards comprised of two IIS (PCB-030, -207), two PIS (PCB-155, -204), 128 PCB congeners found in Aroclors $\AA$ at levels greater then 0.05 weight percent, and 16 PCB congeners found at less than this level. The capillary GC-ECD data were collected, archived in digital form, and processed using chromatography data-system software. Up to nine levels of calibration for each individual congener were used to quantify the targeted congeners. The calibration curve covers a concentration range of $0.01-0.03$ to $100 \mathrm{ng} \cdot \mathrm{mL}^{-1}$ of each congener. 


\section{Polychlorinated Dibenzo-p-Dioxin and Dibenzofuran Analysis}

Instrumental internal standards were added to each PCDD/DF fraction and the final volume adjusted to about 25-50 $\mu \mathrm{L}$. PCDFs and PCDDs were determined by gas chromatography with high-resolution mass spectrometric detection (GC-HRMS) by monitoring five sequential mass windows of selected ions for the $\mathrm{Cl}_{4-8}$ PCDFs and PCDDs during the chromatographic separation. Analyses were performed using heated direct on-column injection onto a retention gap connected to a $30 \mathrm{~m}$ x $0.15 \mathrm{~mm}$ x $0.1-\mu \mathrm{m}$ film thickness 5 percent phenyl-, 95 percent methylsilicone capillary column. The analytical column was directly interfaced to the MS. The HRMS system was tuned to a mass resolution of 10,000 and calibrated using perfluorotetradecahydrophenanthrene, and mass windows were established for five ion groups and monitored sequentially during the temperature program. Within each mass window, the two most abundant ions were measured for positive identification and quantification of each analyte; additional ions were monitored for any responses from potentially interfering chemicals (for example, $\mathrm{Cl}_{5-9}$ polychlorinated diphenyl ethers, $\mathrm{Cl}_{5-7}$ polychlorinated terphenyls, $\mathrm{Cl}_{6-7}$ polychlorinated naphthalenes, and others), for $\mathrm{Cl}_{3-8}$ dibenzothiophenes, and $\mathrm{Cl}_{3-8}$ phenanthrenes and anthracenes. Isotope dilution calibration curves describing the response of each native congener (from 0.1 to $1,000 \mathrm{pg} \cdot \mu \mathrm{L}^{-1}$ ) to that of a labeled procedural internal standard congener were used.

Window switching times were established using a window-defining PCDF/PCDD standard mixture; relative retention times were then established for polychlorinated dibenzothiophenes and other compounds of interest. Chromatographic columns were selected and temperature programmed on the basis that they must resolve 2,3,7,8-TCDD from 1,2,3,7/1,2,3,8-TCDD (and from 1,2,3,4-TCDD) by a resolution factor of at least 0.5 . Column performance was verified by analyzing standards of individual components, and observing the chromatographic resolution of the TCDDs, hexachlorodibenzo- $p$-dioxins and dibenzofurans (HxCDDs and $\mathrm{HxCDFs).} \mathrm{Similarly,} \mathrm{relative} \mathrm{retention} \mathrm{times} \mathrm{for} \mathrm{all} \mathrm{other}$ congeners of interest were evaluated with respect to labeled analogs.

Calibration curves describing the response of each native congener to that of a labeled procedural internal standard congener were used directly in the calculations, and their ranges of values were determined in the calibration procedure. Each calibration curve was matched to the range of analyte responses in the sample set.

\section{Secondary Sample Preparation-Additional OC Samples}

Because of the very low concentrations of PCBs that were anticipated in these samples, the cleanliness of all equipment was verified prior to any application of the extracts to a preparation step. The automated, multi-sample fractionation systems, HP-SEC and HP-PGC, were of special concern because they could be likely sources of sample carryover in preparation work. To minimize the potential for this to occur, the following checks were performed and the fractions analyzed prior to sample preparation; also, QC samples were added to the sample set to demonstrate the [low] levels of carryover throughout the preparation scheme.

The HP-SEC and the HP-PGC systems were demonstrated to be free of PCB background. All injector lines were thoroughly cleaned or replaced as necessary. Multiple solvent injection cycles were processed to equilibrate each system. Then, triplicate solvent blanks were collected and analyzed for PCBs. Each system was considered acceptably clean if levels of PCBs are less than $50 \mathrm{ng}$ (total) with no single c-PCB contributing greater than $1 \mathrm{ng}$; otherwise, the systems were recleaned and further blanks evaluated.

Three separate procedural blanks were incorporated into the secondary portion of the sample preparation scheme to demonstrate the cleanliness of the post-dialysis part of the overall sample preparation plan. These procedural blanks were in addition to the procedural blanks previously prepared for the field and dialysis portions of this study. These procedural blanks were prepared and interspersed throughout the sample set, and then processed through the entire secondary scheme: secondary reactive cleanup, HP-SEC, HP-PGC, and LP-BAC for the PCDD/DF fractions. In addition, individual blanks were prepared for each discrete step of the scheme: a) secondary reactive cleanup, b) HP-SEC, c) HP-PGC, and d) LP-BAC; these blanks were used to assess and document the relative contributions of background PCBs (and PCDDs/DFs) from each step of the preparation scheme.

\section{Confirmatory Congener-Specific Polychlorinated Biphenyl Analysis}

Sample chromatography by dual-column GC-ECD exhibited high levels of interferences by coeluting peaks, which limited quantification of PCB-014, PCB-029, and PCB-050, the polychlorinated biphenyl congeners selected for use as PRCs in this study. All sample and field blank extracts were reanalyzed by gas chromatography with quadrupole mass spectrometric detection (GC-QMS) using both full-scan and selected-ion recording (SIR) for quantification of these congeners. Polychlorinated biphenyl congeners were determined by GC-QMS by monitoring selected ions for the $\mathrm{Cl}_{1-10}$ PCBs during the chromatographic separation. Analyses were performed using cool on-column injection onto a retention gap connected to a $40 \mathrm{~m} \times 0.18 \mathrm{~mm} \times 0.1-\mu \mathrm{m}$ film thickness 5 percent phenyl-, 95 percent methylsilicone capillary column. The analytical column was directly interfaced to the MS. The MS system was tuned to a mass resolution of 1,000 and calibrated using perfluorotributylamine, and the mass window was established for one ion group encompassing the two most abundant $\mathrm{Cl}_{1-10}$ $\mathrm{PCBs}$ and monitored during the temperature program. Within 
Development of Total Maximum Daily Loadings for the Bluestone River Watershed, Virginia and West Virginia

the mass window, the two most abundant ions were measured for positive identification and quantification of each analyte. Internal standard calibration curves describing the response of each congener to that of a procedural internal standard congener were used. Additional full-scan mass spectrometric analyses were conducted to confirm suspected interferences.

\section{Quality Assurance and Quality Control}

An operational QC system of checks was used to control and assess the quality of measurements. This system of checks was managed by a quality assurance (QA) system that ensures that defined standards of quality are being met (at stated levels of confidence). The accuracy and precision of environmental methods were assessed by utilizing appropriate checks for sample preparation and instrumental analysis. The appropriate QC sample types were selected on the basis of applicability to the objectives of this study and incorporated into the analysis plans.

Replicates, fortified field blanks, field blanks, fortified fabrication blanks, and fabrication blanks were prepared during the manufacture of SPMDs for deployment. The fortified field blanks and the fortified fabrication blanks were fortified with native analytes during fabrication. In addition to these QC samples, three procedural blanks were prepared to evaluate laboratory background levels of an analyte or background interferences with an analyte signal from the preparation method; and two fortification verification solutions were prepared to confirm analyte fortification levels.

\section{Results and Discussion}

Semipermeable membrane devices for the VADEQ and WVDEP parts of this study were prepared together and the samplers were shipped to VADEQ on September 13, 2005. Sampling began on September 15, 2005, for all VADEQ sites; October 1, 2005, for WVDEP Sites 1 and 2, Beacon Cave; and October 5, 2005, for WVDEP Site 3, Morris Spring. All deployed samples consisted of six standard SPMDs per site. Samples were transported to and from the site in precleaned sealed cans placed on ice. Field blanks were shipped, transported, and handled in the field in a manner consistent with the actual samples. All sampling equipment was cleaned prior to sampling and cleaned after each use. Most VADEQ samples were collected on November 1, 2005, with VADEQ Site-11, Cross-tributary to Beaverpond Branch collected on November 14, 2005. WVDEP samples for Sites 1 and 2, Beacon Cave, were collected on October 29, 2005; WVDEP Site-3, Morris Spring was collected on November 14, 2005. All sampling devices were retrieved without losses. All samples were stored at $-20{ }^{\circ} \mathrm{C}$ in sealed cans placed in coolers, and were handled under chain of custody. Samplers were shipped overnight and received at the Columbia Environmental Research Center on November 15, 2005. The samples were inventoried, checked, and stored at $-20^{\circ} \mathrm{C}$. The SPMD samples deployed and collected from the Bluestone River watershed, Tazewell County, Virginia, and Mercer County, West Virginia (Waterbody VASN36/N37R) are listed in table 1.

The SPMDs from VADEQ and WVDEP were treated as one set throughout sample preparation, analysis, and data reduction. Initial sample preparation entailed fortifying all samples with procedural internal standards, sample dialysis, compositing and concentration, along with preparation of quality control samples. Secondary sample preparation involved enrichment and purification of the SPMD dialysates through a series of cleanup and fractionation steps: secondary reactive cleanup, HP-SEC, HP-PGC, and an additional LPBAC step for the PCDD/DF fractions from HP-PGC.

The instrumental analysis plan initially required only two analyses: congener-specific PCB analysis by dual-column GCECD, and 2,3,7,8-PCDD/DF/homolog analysis by GC-HRMS. However, additional perdeuterated PAH PRCs were incorporated into the study for comparison with the c-PCB PRCs, and required a separate analysis. Significant chromatographic interferences with the c-PCB PRC results required further GC-QMS analyses to obtain more reliable PRC information. In addition to unidentified chromatographic interferences, high levels of OCPs and PBDEs prompted semiquantitative analysis of the pesticides in these samples.

\section{SPMD Accumulation of Selected Congeners of Polychlorinated Biphenyls}

Amounts of total PCBs, PCDDs, and PCDFs accumulated by SPMDs at study sites are summarized in table 2. Amounts of PCB congeners in the composite samples were adjusted for recoveries of procedural internal standards and then corrected for background by subtraction of average field blank levels of PCBs. Low molecular weight congeners (PCB-001-PCB035) are typically adjusted using PCB-029; however, in this study PCB-029 was used as a PRC and therefore its use as a PIS was precluded and these congeners were adjusted using PCB-155. A reporting limit of 0.03 ng per 6-SPMD composite was established for PCB congeners, with the exception of PCB-001, 002, and 003, wherein, a reporting limit of $0.3 \mathrm{ng}$ was established. Congeners with coeluting chromatographic interferences were flagged, omitted from the final tabulations, and were not included in the summations for total amounts of PCBs, or in the calculation of PCB concentrations in water. Concentrations for chromatographically unresolved PCB congeners were calculated from the 5 percent phenyl and the 50 percent phenyl column information. Concentrations were averaged for PCB congeners resolved on both the 5 percent phenyl and the 50 percent phenyl columns. High levels of four organochlorine pesticides were determined to coelute, each with a specific PCB congener: PCB-063-heptachlor epoxide; PCB-090-cis-chlordane; PCB-093-trans-nonachlor; and PCB196-methoxychlor. Therefore, these values were omitted. High levels of tetrabrominated diphenyl ether congener 047 
Table 1. SPMD samples deployed and collected from the Bluestone River watershed, Tazewell County, Virginia, and Mercer County, West Virginia (Waterbody VAS-N36/N37R).

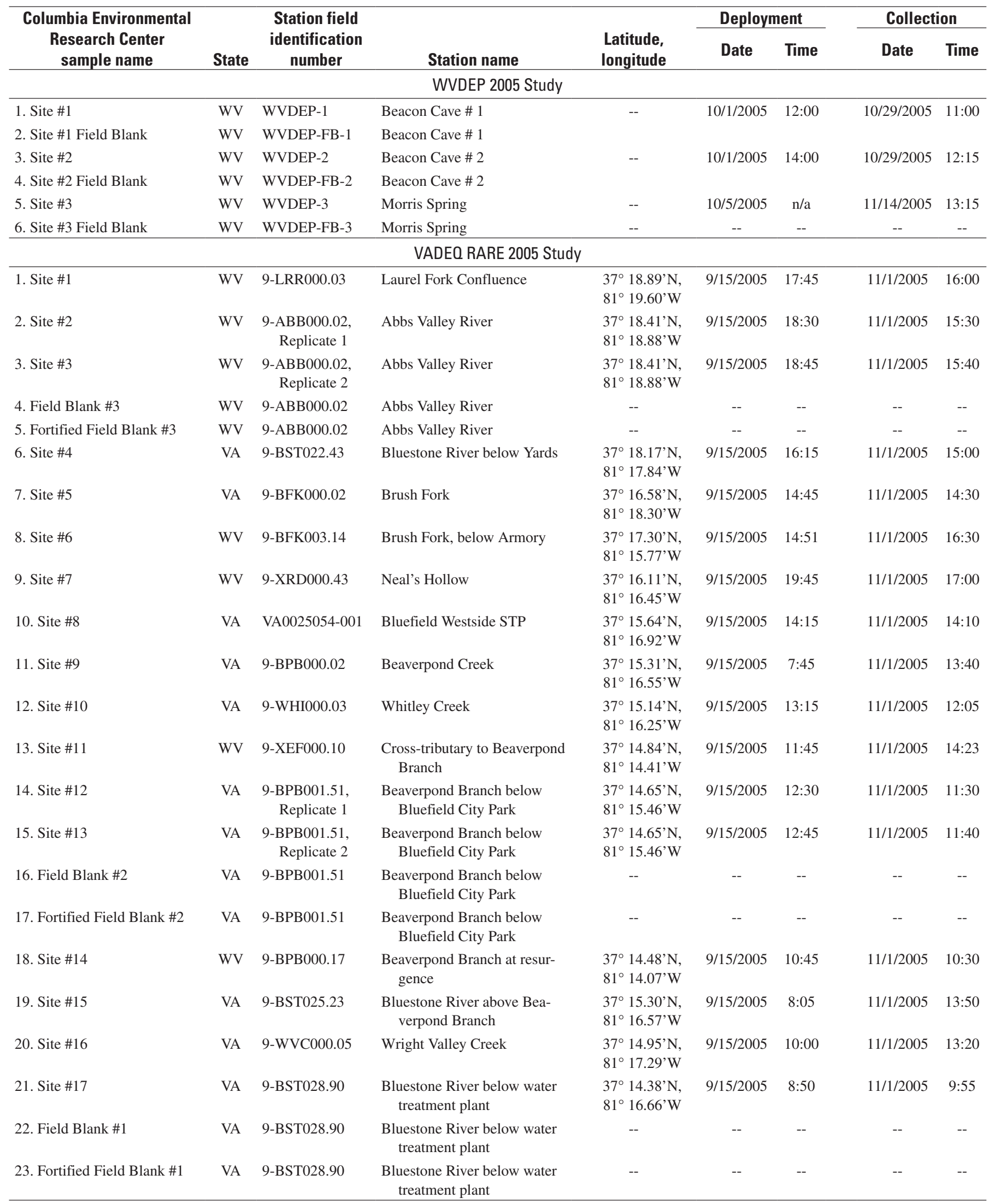


Table 2. Amounts of total polychlorinated biphenyls (PCBs), total polychlorinated dibenzo-p-dioxins (PCDDs) and total polychlorinated dibenzofurans (PCDFs) per semipermeable membrane device (SPMD) composite sample for the Bluestone River watershed sample set, fall 2005.

[Total PCBs are reported in ng per composite, and total PCDDs and total PCDFs are reported in pg per composite]

\begin{tabular}{|c|c|c|c|c|c|}
\hline Sample name & $\begin{array}{c}\text { Field identification } \\
\text { number }\end{array}$ & Field sample label & Total PCBs & Total PCDDs & Total PCDFs \\
\hline \multicolumn{6}{|c|}{ VADEO } \\
\hline Site \#1 & 9-LRR000.03 & Laurel Fork Confluence & 530 & 700 & 380 \\
\hline Site \#2 & $\begin{array}{c}\text { 9-ABB000.02, } \\
\text { Replicate } 1\end{array}$ & Abbs Valley River & 140 & 340 & 110 \\
\hline Site \#3 & $\begin{array}{c}\text { 9-ABB000.02, } \\
\text { Replicate } 2\end{array}$ & Abbs Valley River & 130 & 370 & 130 \\
\hline Site \#4 & 9-BST022.43 & Bluestone River below Yards & 1,400 & 2,200 & 690 \\
\hline Site \#5 & 9-BFK000.02 & Brush Fork & 2,500 & 670 & 300 \\
\hline Site \#6 & 9-BFK003.14 & Brush Fork, below Armory & 190 & 580 & 260 \\
\hline Site \#7 & 9-XRD000.43 & Neal's Hollow & 280 & 980 & 450 \\
\hline Site \#8 & VA0025054-001 & Bluefield Westside STP & 1,300 & 1,900 & 740 \\
\hline Site \#9 & 9-ВРВ000.02 & Beaverpond Creek & 1,300 & 2,700 & 920 \\
\hline Site \#10 & 9-WHI000.03 & Whitley Creek & 1,000 & 1,000 & 920 \\
\hline Site \#11 & 9-XEF000.10 & Cross-tributary to Beaverpond Branch & 1,500 & 6,600 & 1,500 \\
\hline Site \#12 & $\begin{array}{c}\text { 9-BPB001.51, } \\
\text { Replicate 1 }\end{array}$ & Beaverpond Branch below Bluefield City Park & 1,500 & 2,500 & 470 \\
\hline Site \#13 & $\begin{array}{r}\text { 9-BPB001.51, } \\
\text { Replicate } 2\end{array}$ & Beaverpond Branch below Bluefield City Park & 2,100 & 3,100 & 530 \\
\hline Site \#14 & 9-BPB000.17 & Beaverpond Branch at resurgence & 15,000 & 1,800 & 550 \\
\hline Site \#15 & 9-BST025.23 & Bluestone River above Beaverpond Branch & 780 & 1,000 & 370 \\
\hline Site \#16 & 9-WVC000.05 & Wright Valley Creek & 290 & 750 & 400 \\
\hline Site \#17 & 9-BST028.90 & Bluestone River below water treatment plant & 140 & 810 & 150 \\
\hline \multicolumn{6}{|c|}{ WVDEP } \\
\hline Site \#1 & WVDEP-1 & Beacon Cave \# 1 & 20,000 & 1,600 & 630 \\
\hline Site \#2 & WVDEP-2 & Beacon Cave \# 2 & 11,000 & 1,400 & 460 \\
\hline Site \#3 & WVDEP-3 & Morris Spring & 550 & 335 & 140 \\
\hline
\end{tabular}

coeluted with PCB-180, which also was omitted. Unidentified chemicals were found to coelute with three additional PCB congeners (PCB-003, PCB-025, and PCB-101), again, these values were omitted.

Total amounts of PCBs in field samples ranged from 130 to $20,000 \mathrm{ng}$, much greater than field blank amounts (40-53 ng). Three groups of sites are apparent: low (130-530 ng); medium (550-2,500 ng); and high (11,000-20,000 ng).

Amounts of PCBs determined in the three high sites: Beacon Cave \#1 and \#2, and Beaverpond Branch at resurgence \#14, are about seven- to tenfold higher than the amounts determined for the medium group of sites.

Procedural internal standard recoveries for all samples ranged from 62 to 125 percent for PCB-155 and from 71 to 111 percent for PCB-204, excluding VADEQ Site-10, Whitley Creek, and WVDEP Site-3, Morris Spring. Whitley Creek recoveries ranged from 18 to 24 percent as a result of sample preparatory losses. Morris Spring recoveries were 175 percent and 140 percent, respectively; no explanation for this discrepancy was found.

As anticipated, background amounts of PCB congeners in quality-control samples incrementally increased for each additional sample preparation step in the sample processing scheme. The PIS solution used for recovery determination had amounts of only five congeners greater than the reporting limits. Four of these congeners (PCB-001, 006, 100, and 197) ranged from the reporting limits to less than threefold greater than these limits.

Values for all congeners in preparatory blanks for each cleanup or fractionation step were less than or very close to the reporting limits, with total amounts of PCBs ranging from 2.6 to $5.0 \mathrm{ng}$. Average total amounts of PCBs in procedural blanks were $11 \mathrm{ng}$, and average total amounts of PCBs in dialysis processing blanks were $21 \mathrm{ng}$. The contribution from the fabrication blank (materials for a six-SPMD composite plus all sample preparation) was $54 \mathrm{ng}$ of total PCBs. The total amounts of PCBs in all six field blanks ranged from 40 to 53 ng (average $44 \mathrm{ng}$ ).

Analytical precision for the native PCB fortification solution (Aroclor ${ }^{\circledR}$ 1242:1248:1254:1260, 1,000 ng nominal amount fortified) averaged 6.6 percent, and the total PCB recovery for the solution was $870 \pm 10 \mathrm{ng}$; the measured amounts of the congeners were used in the subsequent recovery calculations for fortified samples. Recoveries of individual 
congeners ranged from 53 to 118 percent and averaged $102 \pm$ 21 percent. Recoveries of individual congeners in the fortified field blank samples ranged from 41 to 173 percent and averaged $100 \pm 16$ percent. It should be noted that the mixed Aroclor@ standard used for fortification had very low concentrations of some PCB congeners, which biased the reported recovery ranges for analytes near the reporting limit; the majority of congeners, with amounts several-fold greater than the reporting limits, were quantitatively recovered.

Precision, calculated as relative difference between site replicates, generally was excellent. Relative differences varied more for those replicates with greater total amounts of PCBs (24 percent, VADEQ Site \#12 and \#13 samples) than for the replicates with lesser total amounts of PCBs (5 percent, VADEQ Site \#2 and \#3 samples).

\section{SPMD Accumulation of 2,3,7,8-Substituted Congeners and Homologs of Polychlorinated Dibenzo-p-Dioxins and Dibenzofurans}

Total amounts of PCDDs and of PCDFs for the Bluestone River watershed sample set are summarized in table 2. Amounts of 2,3,7,8-substituted congeners and homologs of PCDDs and PCDFs in the six-SPMD composite samples from the Bluestone River watershed (inherently adjusted for recoveries of PIS) were corrected for background by subtraction of average field blank levels of PCDDs and PCDFs.

The site groupings for PCDDs and PCDFs do not parallel those for PCBs; the three very high-level PCB sites corresponded to sites with only mid-range total amounts of PCDDs and PCDFs. Total amounts of PCDDs and PCDFs were found at very high levels at only one site: VADEQ Site-11, Crosstributary to Beaverpond Branch. At this site PCDDs were twofold greater than average, and PCDFs were about 50 percent greater than the next highest group of sites (VADEQ Site-9, Beaverpond Creek; VADEQ Site-10, Whitley Creek; and VADEQ Sites-12 and 13, Beaverpond Branch below Bluefield City Park). The remaining sites exhibited a gradual increase in amounts of PCDDs and PCDFs with no significant site groupings into low, medium, or high levels of PCDDs/DFs.

Of the 2,3,7,8-substituted congeners, octachlorodibenzofuran (OCDF) and 1,2,3,4,6,7,8-heptachlorodibenzofuran (HpCDF) contributed largely to total amounts of PCDFs; only OCDD contributed significantly to the total amount of PCDDs. Amounts of homologs (summed amounts of 2,3,7,8-substituted plus non-2,3,7,8-substituted congeners) were correlated differently with total amounts of PCDDs or PCDFs than were the 2,3,7,8-substituted congeners. Homolog amounts of TCDFs contributed most significantly to the total amount of PCDFs. All PCDF homolog groups were similarly correlated with total amounts of PCDFs. Amounts of TCDD and OCDD homologs contributed largely and about equally to the total amount of PCDDs, and as with the PCDFs, all PCDD homolog groups were similarly correlated with total amounts of PCDDs.
The TCDF homologs were comprised of complex mixtures of TCDF congeners, the profiles of which did not change significantly among sites. The TCDD homolog series were found to be very different in composition compared with the TCDF homolog series. Of special note was that one specific non-2,3,7,8-substituted congener of PCDDs contributed to the majority of TCDD homologs and to total PCDDs. This congener has been tentatively identified as either 1,2,3,7-TCDD or 1,2,3,8-TCDD, members of an unresolved chromatographic pair on the 5 percent phenyl-, 95 percent methylsilicone capillary column.

Procedural internal standard recoveries for all samples ranged from 48 to 114 percent (average $70 \pm 19$ percent), excluding VADEQ Site-10, Whitley Creek because of sample preparatory losses (average recovery 14 percent). The analytical isotopic dilution method used here, inherently corrected for these preparatory losses. No inconsistencies in recoveries for the WVDEP Site-3 sample were found, indicating that only the post HP-PGC c-PCB fraction of the sample was compromised.

Preparatory blanks for the HP-PGC and LP-BAC steps were less than or very close to the reporting limits for all congeners, with total amounts of PCDDs and total PCDFs ranging from 2 to $4 \mathrm{pg}$. Average total amounts of PCDDs and PCDFs in procedural blanks ranged from 4 to $7 \mathrm{pg}$, and average total amounts of PCDDs and PCDFs in dialysis processing blanks ranged from 6 to $11 \mathrm{pg}$. The total amounts of PCDDs and PCDFs contributed from the fabrication blank were $24 \mathrm{pg}$ and $14 \mathrm{pg}$, respectively. The average total amounts of PCDDs and PCDFs in VADEQ field blanks ranged from 14 to $17 \mathrm{pg}$ and from 9 to $12 \mathrm{pg}$, and average total amounts in WVDEP field blanks ranged from 13 to $17 \mathrm{pg}$ and from 4 to $5 \mathrm{pg}$, respectively. Average recoveries of native PCDD and PCDF congeners in the fortified field blank samples ranged from 69 to 104 percent.

Analytical precision for the native PCDD/DF fortification solution (fortified at 8,640 pg PCDDs and 12,240 pg PCDFs) averaged 3 percent. Recoveries of total amounts of PCDDs and PCDFs for the solution were 8,300 $\pm 100 \mathrm{pg}$ and $12,000 \pm 100$

$\mathrm{pg}$, respectively. Individual congener recoveries ranged from 93 to 100 percent (average $95 \pm 3$ percent) for PCDDs and from 86 to 105 percent (average $97 \pm 5$ percent) for PCDFs. These measured amounts of the congeners were used in the subsequent recovery calculations for fortified samples. Individual congener recoveries in the fortified fabrication blank sample ranged from 102 to 108 percent; however, recoveries of individual congeners in the fortified field blank samples ranged from 56 to 104 percent. Recoveries of all PCDD congeners in these samples were consistently 97-105 percent.

Precision of PCDD/DF accumulation between site replicates was generally excellent with differences of less than 20 percent for between total amounts of PCDDs and PCDFs in both replicate samples. As discussed for replication between sites for total amounts of PCBs, relative differences between replicate samples were found to be inversely related to the total amounts of PCDDs and PCDFs. 


\section{SPMD Release of Performance Reference Compounds (PRCs)}

Initial amounts of PRCs in the six-SPMD composite samples before exposure were defined as the average of amounts determined in PRC-fortified field blank samples associated with VADEQ or with WVDEP sites (samplers not undergoing release of PRCs by environmental exposure). Overall average values from both sets of field blanks were not used because of small yet significant differences in averaged values between each set of sites. Final amounts of PRCs in SPMDs were defined as the amounts determined in field samples after exposure.

The c-PCB PRC amounts were adjusted for recoveries of PIS PCB-155. The PAH- $d$ PRCs were quantified after dialysis and were not adjusted for recovery; however, values for the PAH- $d$ PRCs were included in this study to enable comparisons of PCB and PAH- $d$ release rates. Amounts of c-PCB and PAH- $d$ PRCs in the associated blank samples were less than the reporting limits, therefore, neither the c-PCB nor the PAH- $d$ PRC values were corrected for background. The dual-column GC-ECD values indicated positive biases for the c-PCB PRCs resulting from interfering compounds, therefore, subsequent SIR GC-QMS confirmations of the c-PCB PRCs were performed. Percentages of PRCs remaining in field samples at the end of exposures were determined by comparing the final amounts of PRCs measured in the samples to the initial amounts of PRC and are summarized in table 3.

Amounts of PRCs remaining in SPMDs after exposure ranged from $<0.1$ percent (not detectable) to much greater than 100 percent. Significant interferences in the quantification of some PRCs in some samples were indicated by recoveries of amounts in SPMDs greater than those initially fortified. Interferences in quantifying c-PCB PRCs are most evident in samples from Site-5 (Brush Fork), Site-14 (Beaverpond Branch at resurgence), and WVDEP-1 and 2 (Beacon Cave \#1 and \#2). These samples contained high total amounts of PCBs (2,500-20,000 ng), including amounts of PCB-014, PCB-029, and PCB-050 that, when accumulated in SPMDs, approached those amounts added initially as PRCs for monitoring release. No coeluting or interfering congeners for the confirmatory SIR GC-QMS analysis were noted. However, finding [of] high amounts of PCB congeners previously not considered to be present in the environment at significant levels, suggests that additional caution must be employed for the selection of candidate PRCs and for the selection of subsequent analytical methods for PRCs, as environmental levels of these compounds or analytical interferences with these compounds were much more prevalent than first assumed.

Table 3. Percentages of performance reference compounds (PRCs) remaining in semipermeable membrane device (SPMD) composite samples from the Bluestone River watershed sample set, fall 2005.

Performance Reference Compounds

Sample name Acenaphthylene-d Acenaphthene-d Fluorene-d Phenanthrene-d PCB-014 Pyrene-d PCB-029 PCB-050

\begin{tabular}{|c|c|c|c|c|c|c|c|c|}
\hline \multicolumn{9}{|c|}{ VADEO } \\
\hline Site \#1 & 22 & $<0.1$ & 20 & 32 & 72 & 72 & 88 & 94 \\
\hline Site \#2 & 21 & 39 & 32 & 27 & 85 & 45 & 86 & 88 \\
\hline Site \#3 & 5.5 & 29 & 32 & 40 & 80 & 61 & 87 & 86 \\
\hline Site \#4 & 4.1 & 19 & 35 & 31 & 74 & 86 & 85 & 84 \\
\hline Site \#5 & 29 & 46 & 28 & 30 & 90 & 78 & 100 & 100 \\
\hline Site \#6 & 23 & 49 & 37 & 98 & 67 & 86 & 79 & 80 \\
\hline Site \#7 & 12 & $<0.1$ & 25 & 23 & 64 & 65 & 76 & 80 \\
\hline Site \#8 & 32 & 8.6 & 33 & 70 & 99 & 96 & 97 & 100 \\
\hline Site \#9 & 18 & 11 & 37 & 40 & 60 & 51 & 75 & 89 \\
\hline Site \#10 & 14 & $<0.1$ & 83 & 50 & 33 & 56 & 49 & 57 \\
\hline Site \#11 & 18 & 14 & 41 & 41 & 40 & 100 & 55 & 83 \\
\hline Site \#12 & 18 & 6.5 & 49 & 61 & 48 & 100 & 63 & 78 \\
\hline Site \#13 & 19 & 5.4 & 27 & 65 & 42 & 130 & 58 & 75 \\
\hline Site \#14 & 12 & 1.1 & 32 & 12 & 87 & 55 & 110 & 180 \\
\hline Site \#15 & 6.8 & 1.1 & 25 & 41 & 58 & 86 & 72 & 79 \\
\hline Site \#16 & 14 & 1.1 & 27 & 18 & 54 & 65 & 66 & 71 \\
\hline Site \#17 & 9.6 & 9.7 & 30 & 36 & 59 & 77 & 70 & 72 \\
\hline \multicolumn{9}{|c|}{ WVDEP } \\
\hline Site \#1 & 13 & 20 & 29 & 24 & 91 & 75 & 120 & 220 \\
\hline Site \#2 & 16 & 14 & 40 & 30 & 92 & 78 & 110 & 160 \\
\hline Site \#3 & 19 & 23 & 50 & 27 & 14 & 100 & 31 & 50 \\
\hline
\end{tabular}




\section{Calculation of Estimated Concentrations of PCBs, PCDDs, and PCDFs in Water}

Concentrations of PCBs, PCDDs, and PCDFs in water were estimated using the PRC-adjusted empirical uptake rate model incorporated into a spreadsheet calculator program (Huckins and others, 2006). Because of the availability of c-PCB and PAH- $d$ PRC information, all PRC values were investigated for use in calculating estimates of the concentrations of target compounds in water. The final PRC amounts for PCB-014, PCB-029, and PCB-050 were determined by GC-QMS and were corrected for PCB-PIS recovery; final PRC amounts for acenaphthylene- $d$, acenaphthene- $d$, fluorene- $d$, phenanthrene- $d$, and pyrene- $d$ were determined by gas chromatography with flame ionization detection of dialysates and were not corrected for recovery. Initial PRC amounts were determined from the average of SPMD field blank samples associated with VADEQ or with WVDEP sites using the methods just described. Overall average values from both sets of field blanks were not used because of differences between each set of sites. Final PRC amounts were determined in each SPMD field sample. PRC intercepts $\left(a_{O P R C}\right)$ within each site and among sites were calculated using PRC-adjusted empirical uptake rate model and represent a measure of the sampling rate. The $a_{O P R C}$ values were reviewed; data were omitted for PRCs at sites in which the final PRC amounts were not detectable $(<0.01 \mu \mathrm{g}$ for PAH- $d)$ and in which the final PRC amounts were greater than the initial amounts (interferences or accumulation of PRC compounds from the site). Comparison of $a_{O P R C}$ values among and between all sites was used to establish an acceptable range of PRC ratios (final amount/initial amount) for selecting $a_{O P R C}$ values and for omitting outliers prior to averaging values at each site. Calculations provided similar values of $a_{O P R C}$ over a broad range of releases, from PRC releases of only a few percent to those that were nearly quantitative. After data review, accepted values of $\mathrm{a}_{\text {OPRC }}$ were averaged for use and are summarized in table 4 .

The total volumes of water sampled ranged from 40 to 2,300 L. At each site, sampling rates were maximum for $\mathrm{Cl}_{2-3}$ PCBs, which ranged from 690 to 2,300 L of water sampled, and decreased about 17-fold to $40-140 \mathrm{~L}$ for $\mathrm{Cl}_{7-8}$ PCDDs/ DFs. Across sites, sampling rates for the same analytes varied by only about three- to fourfold. This indicated that average water flows encountered by the deployed SPMDs were somewhat similar, possibly because the deployment structures had a greater effect on mediating flow to the SPMD surfaces more than differences in bulk streamflows outside the structures had in directly affecting flow at the SPMD surfaces.

The uncertainty factor for estimating concentrations of compounds in water from SPMD accumulation using PRC release data was calculated from the antilog of the standard deviation of the log-based $a_{O P R C}$ values (table 4). Using these estimates of uncertainty, the uncertainties of most estimated concentrations in water were less than about \pm twofold, with the exception of Sites-12 and 13 (Beaverpond Branch below
Bluefield City Park) which were about twofold and Site WVDEP-3 (Morris Spring) which was about threefold.

\section{Concentrations of Selected Congeners of Polychlorinated Biphenyls in Water}

Amounts of PCB congeners in SPMDs were adjusted for recoveries of PIS and were corrected for background amounts of c-PCBs in the associated field blank samples prior to calculation of the estimated concentrations in water. Specific PCB congeners with interferences from high levels of OCPs or PBDEs were omitted from the concentration calculations, as were congeners with unidentified co-eluting compounds. For PCB congeners less than the reporting limit, the reporting limit value was used in the calculation of the concentration of the congener in water. This resulted in minimum concentrations of congeners in water of about $1 \mathrm{pg} \cdot \mathrm{L}^{-1}$. Congener values less than the reporting limit were not included in total PCB concentrations.

Estimated concentrations of PCB congeners in water and estimated total concentrations of PCBs in water, calculated as the sum of all detectable concentrations of PCB congeners in water, are presented in table 5, at the end of this report. Estimated total concentrations of PCBs at study sites ranged from 130 to $18,000 \mathrm{pg} \cdot \mathrm{L}^{-1}$ (table 6) and were found to be linearly related to the relative amounts of PCBs accumulated by SPMDs.

The lowest estimated PCB concentration in water (130 $\left.\mathrm{pg} \cdot \mathrm{L}^{-1}\right)$ is almost threefold greater than total hypothetical concentrations of field blank amounts of PCBs (about 50 $\left.\mathrm{pg} \cdot \mathrm{L}^{-1}\right)$. As discussed previously for amounts of PCBs, three groups of sites are apparent for PCB concentrations in water: low (130-350 pg. $\left.\mathrm{L}^{-1}\right)$; medium $\left(640-3,500 \mathrm{pg} \cdot \mathrm{L}^{-1}\right)$; and high $\left(11,000-18,000 \mathrm{pg} \cdot \mathrm{L}^{-1}\right)$. Concentrations of PCBs in water estimated at the three high sites: Beacon Cave \#1 and \#2, and Beaverpond Branch at resurgence \#14, are about four- to sixfold higher than concentrations estimated for the medium group of sites.

\section{Concentrations of 2,3,7,8-Substituted Congeners and Homologs of Polychlorinated Dibenzo- $p$ - Dioxins and Dibenzofurans in Water}

Amounts of 2,3,7,8-substituted congeners and homologs of PCDDs and PCDFs in the six-SPMD composite samples from the Bluestone River watershed were inherently adjusted for recoveries of PIS by the isotopic dilution mass spectrometric technique used, and were corrected for background amounts of c-PCBs in the associated field blank samples prior to calculation of the estimated concentrations in water. Concentrations of PCDD and PCDF congeners with levels less than the reporting limit were derived from the reporting limit of the congeners in water. This resulted in minimum estimated concentrations of congeners in water of about 0.2 
Table 4. Average $\mathrm{a}_{\text {OPRC }}$ intercept values of performance reference compounds (PRCs), maximum and minimum volumes of water sampled, and estimated uncertainties in sampling rates for semipermeable membrane device composite samples from the Bluestone River watershed sample set, fall 2005.

[Volumes of water for PCB are reported in $\mathrm{L}$ and are calculated for $\log \mathrm{K}_{\mathrm{ow}} 5.3$ (maximum) and $\log \mathrm{K}_{\mathrm{ow}} 7.8$ (minimum). Volumes of water for PCDDs and PCDFs are reported in $\mathrm{L}$ and are calculated for $\log \mathrm{K}_{\mathrm{ow}} 6.8$ (maximum) and $\log \mathrm{K}_{\mathrm{ow}} 9.8$ (minimum). Relative uncertainties are reported as multipliers/divisors of estimated concentrations]

\begin{tabular}{|c|c|c|c|c|c|c|}
\hline \multirow[b]{2}{*}{ Sample name } & \multirow[b]{2}{*}{$a_{\text {OPRC }}$} & \multicolumn{2}{|c|}{ Polychlorinated biphenyls } & \multicolumn{2}{|c|}{$\begin{array}{l}\text { Polychlorinated dibenzo- } p \text {-dioxins } \\
\text { and dibenzofurans }\end{array}$} & \multirow{2}{*}{$\begin{array}{c}\text { Relative } \\
\text { uncertainty }\end{array}$} \\
\hline & & Maximum & Minimum & Maximum & Minimum & \\
\hline \multicolumn{7}{|c|}{ VADEO } \\
\hline Site \#1 & -3.51 & 1,200 & 250 & 730 & 71 & 1.29 \\
\hline Site \#2 & -3.54 & 1,100 & 240 & 680 & 66 & 1.67 \\
\hline Site \#3 & -3.54 & 1,100 & 230 & 680 & 66 & 1.33 \\
\hline Site \#4 & -3.55 & 1,100 & 230 & 660 & 64 & 1.27 \\
\hline Site \#5 & -3.65 & 860 & 180 & 520 & 51 & 1.56 \\
\hline Site \#6 & -3.58 & 1,000 & 220 & 620 & 61 & 1.51 \\
\hline Site \#7 & -3.38 & 1,600 & 340 & 980 & 95 & 1.13 \\
\hline Site \#8 & -3.75 & 690 & 150 & 420 & 41 & 1.67 \\
\hline Site \#9 & -3.44 & 1,400 & 300 & 870 & 84 & 1.55 \\
\hline Site \#10 & -3.37 & 1,700 & 350 & 1,000 & 98 & 1.24 \\
\hline Site \#11 & -3.39 & 1,600 & 340 & 970 & 95 & 1.85 \\
\hline Site \#12 & -3.46 & 1,400 & 290 & 830 & 81 & 2.00 \\
\hline Site \#13 & -3.39 & 1,600 & 330 & 960 & 94 & 2.10 \\
\hline Site \#14 & -3.44 & 1,400 & 300 & 860 & 84 & 1.83 \\
\hline Site \#15 & -3.45 & 1,400 & 290 & 840 & 82 & 1.59 \\
\hline Site \#16 & -3.31 & 1,900 & 400 & 1,200 & 110 & 1.35 \\
\hline Site \#17 & -3.38 & 1,600 & 340 & 980 & 85 & 1.42 \\
\hline \multicolumn{7}{|c|}{ WVDEP } \\
\hline Site \#1 & -3.24 & 1,300 & 280 & 800 & 78 & 1.15 \\
\hline Site \#2 & -3.29 & 1,200 & 250 & 720 & 70 & 1.24 \\
\hline Site \#3 & -3.16 & 2,300 & 480 & 1,400 & 136 & 2.70 \\
\hline
\end{tabular}

to about $1 \mathrm{fg} \cdot \mathrm{L}^{-1}$. Qualifiers for PCDD and PCDF congeners (or homologs) not meeting the quality-control criteria were propagated throughout the calculations and remain associated with their respective congener concentration in water. For analytes exceeding \pm 15 percent tolerance in the ratio of the primary and secondary ions used for quantification, the lesser value is reported as the quantification limit and denoted LQ; for analytes not detected in the sample, the specified detection limit is reported and denoted ND. Analytes with recovery of the associated ${ }^{13} \mathrm{C}$-labelled surrogate exceeding the quality control limits set by the method were reported and denoted LR. Total concentrations of PCDDs and PCDFs were derived from the summation of detectable concentrations of each homolog group; therefore, congeners that were undetectable or unquantifiable were not included in concentrations in water of either the homologs or the total PCDDs or PCDFs. Estimated concentrations of 2,3,7,8-substituted congeners, homologs, and total PCDDs and PCDFs in water, calculated as the sum of all detectable concentrations of congeners in water (table 7, at the end of this report).
Estimated concentrations of 2,3,7,8-substituted congeners in water at study sites ranged from $<1$ to $22,000 \mathrm{fg} \cdot \mathrm{L}^{-1}$ and $<1$ to $2,300 \mathrm{fg} \cdot \mathrm{L}^{-1}$ for PCDDs and PCDFs, respectively. Total concentrations of 2,3,7,8-substituted congeners in water were comprised largely of OCDD and OCDF, with less than 10 percent of the total contributed by concentrations of other, mainly 2,3,7,8-heptachloro-congeners.

Of special interest for this study was 2,3,7,8-TCDD, the only PCDD/DF congener with a regulatory SWQC value (1.2 $\mathrm{gg} \cdot \mathrm{L}^{-1}$ or $1,200 \mathrm{fg} \cdot \mathrm{L}^{-1}$; Virginia Water Quality Standards, 2006). Estimated concentrations of 2,3,7,8-TCDD in water ranged from 0.5 to $41 \mathrm{fg} \cdot \mathrm{L}^{-1}$, as calculated from quantifiable amounts of 2,3,7,8-TCDD in SPMDs at the study sites. Concentrations of $2,3,7,8$-TCDD in water were $<5 \mathrm{fg} \cdot \mathrm{L}^{-1}$ at all study sites, except Site \#8 (Bluefield Westside STP) with an estimated concentration of 2,3,7,8-TCDD in water of $41 \mathrm{fg} \cdot \mathrm{L}^{-1}$. Concentrations of 2,3,7,8-sustituted PCDD and PCDF congeners in water followed the same trends as previously described for amounts of 2,3,7,8-sustituted PCDD and PCDF congeners in SPMDs. 
Table 6. Estimated total concentrations in water of polychlorinated biphenyls (PCBs), polychlorinated dibenzop-dioxins (PCDDs) and polychlorinated dibenzofurans (PCDFs) from the Bluestone River watershed sample set, fall 2005.

[Total PCBs are reported in $\mathrm{pg} \cdot \mathrm{L}^{-1}$, and total PCDDs and total PCDFs are reported in $\mathrm{fg} \cdot \mathrm{L}^{-1}$ ]

\begin{tabular}{|c|c|c|c|c|c|}
\hline $\begin{array}{c}\text { Sample } \\
\text { name }\end{array}$ & $\begin{array}{c}\text { Field identification } \\
\text { number }\end{array}$ & Field sample label & PCBs & PCDDs & PCDFs \\
\hline \multicolumn{6}{|c|}{ VADEO } \\
\hline Site \#1 & 9-LRR000.03 & Laurel Fork Confluence & 640 & 4,900 & 980 \\
\hline Site \#2 & $\begin{array}{c}\text { 9-ABB000.02, } \\
\text { Replicate } 1\end{array}$ & Abbs Valley River & 180 & 3,200 & 210 \\
\hline Site \#3 & $\begin{array}{c}\text { 9-ABB000.02, } \\
\text { Replicate } 2\end{array}$ & Abbs Valley River & 180 & 3,700 & 270 \\
\hline Site \#4 & 9-BST022.43 & Bluestone River below Yards & 1,800 & 10,000 & 1,500 \\
\hline Site \#5 & 9-BFK000.02 & Brush Fork & 3,500 & 9,300 & 820 \\
\hline Site \#6 & 9-BFK003.14 & Brush Fork, below Armory & 260 & 6,900 & 630 \\
\hline Site \#7 & 9-XRD000.43 & Neal's Hollow & 260 & 7,200 & 720 \\
\hline Site \#8 & VA0025054-001 & Bluefield Westside STP & 2,300 & 11,000 & 2,300 \\
\hline Site \#9 & 9-ВРB000.02 & Beaverpond Creek & 1,300 & 13,000 & 1,900 \\
\hline Site \#10 & 9-WHI000.03 & Whitley Creek & 910 & 7,100 & 1,600 \\
\hline Site \#11 & 9-XEF000.10 & Cross-tributary to Beaverpond Branch & 1,300 & 36,000 & 4,800 \\
\hline Site \#12 & $\begin{array}{c}\text { 9-BРB001.51, } \\
\text { Replicate 1 }\end{array}$ & Beaverpond Branch below Bluefield City Park & 1,500 & 15,000 & 1,000 \\
\hline Site \#13 & $\begin{array}{r}\text { 9-BPB001.51, } \\
\text { Replicate 2 }\end{array}$ & Beaverpond Branch below Bluefield City Park & 1,700 & 16,000 & 940 \\
\hline Site \#14 & 9-ВРВ000.17 & Beaverpond Branch at resurgence & 13,000 & 17,000 & 2,000 \\
\hline Site \#15 & 9-BST025.23 & Bluestone River above Beaverpond Branch & 800 & 9,100 & 850 \\
\hline Site \#16 & 9-WVC000.05 & Wright Valley Creek & 260 & 5,100 & 770 \\
\hline Site \#17 & 9-BST028.90 & Bluestone River below water treatment plant & 130 & 6,500 & 230 \\
\hline \multicolumn{6}{|c|}{ WVDEP } \\
\hline Site \#1 & WVDEP-1 & Beacon Cave \#1 & 18,000 & 17,000 & 3,500 \\
\hline Site \#2 & WVDEP-2 & Beacon Cave \#2 & 11,000 & 17,000 & 3,000 \\
\hline Site \#3 & WVDEP-3 & Morris Spring & 350 & 1,600 & 160 \\
\hline
\end{tabular}

Estimated total concentrations of PCDDs and PCDFs in water at the study sites ranged from 3,200 to $36,000 \mathrm{fg} \cdot \mathrm{L}^{-1}$ and $210-4,800 \mathrm{fg} \cdot \mathrm{L}^{-1}$, respectively. Total PCDD and PCDF concentrations were calculated as the sum of homolog concentrations in water. Homologs of PCDDs and PCDFs in water were comprised largely of OCDD and OCDF.

Generally, homolog contributions decreased from octa- $>$ hepta- $>$ tetra- $>$ penta- $>$ hexa-chlorodibenzo- $p-$ dioxin and from octa- $>$ tetra- $>$ penta- $>$ hepta- $>$ hexachlorodibenzofuran. SPMDs accumulated significantly greater amounts of $\mathrm{Cl}_{4-5}$ homologs comprising non-2,3,7,8substituted congeners than those comprising only $2,3,7,8$ substituted congeners. The lesser chlorinated congeners contributed very much to the overall PCDD and PCDF concentrations in water.

\section{Acknowledgments}

This study was supported through cooperative agreements with the U.S. Environmental Protection Agency (Interagency Agreement Number 14922025) and the West Virginia Department of Environmental Protection (Agreement Number 06C3WV833500004).

\section{References Cited}

Frame, G.M., Cochran, J.W., and Boewadt, S.S., 1996, Complete PCB congener distributions for 17 Aroclor mixtures determined by 3 HRGC systems optimized for comprehen- 
sive, quantitative, congener-specific analysis: Journal of High Resolution Chromatography, 19:657-668.

Huckins, J.N., Petty, J.D., Orazio, C.E., Lebo, J.A., Clark, R.C., Gibson, V.L., Gala, W.R., Echols, K.R., 1999, Determination of uptake kinetics (sampling rates) by lipidcontaining Semipermeable Membrane Devices (SPMDs) for Polycyclic Aromatic Hydrocarbons (PAHs) in water: Environmental Science and Technology, 33: 3,918-3,923.

Huckins, J.N., Petty, J.D., Lebo, J.A., Almeida, F.V., Booij, K., Alvarez, D.A., Cranor, W.L., Clark, R.C., Mogensen, B.B., 2002, Development of the permeability/performance reference compound approach for in situ calibration of semipermeable membrane devices: Environmental Science and Technology, 36:85-91.

Huckins, J.N., Petty, J.D., Booij, K., 2006, Monitors of organic chemicals in the environment-Semipermeable membrane devices: New York, Springer.

Lott, C,R, Newman, A., 2005, PCBs in the Bluestone River: Virginia Department of Environmental Quality, web publication, accessed on April 21, 2005, at http://www.deq. virginia.gov/tmdl/pptpdf/blstpcb1.pds.
McCarthy, K.A., Gale, R.W., 1999, Investigation of the distribution of organochlorine and polycyclic aromatic hydrocarbon compounds in the Lower Columbia River using semipermeable membrane devices: U.S. Geological Survey Water-Resources Investigation Report 99-4051, 136 p.

Standard Operation Procedures Manual for the (Virginia) Department of Environmental Quality, 2003, Office of Water Quality Monitoring Programs (revision No. 10).

Virginia State Water Control Board, 1997, Water Quality Standards, 9VAC 25-260-5 et seq. Statutory Authority: 62.1-44.15 )3a) of the Code of Virginia.

Virginia Water Quality Standards: 9 VAC 25-260, January, 2006.

West Virginia Environmental Quality Board, 2000, Requirements Governing Water Quality Standards.

Water Quality Monitoring Consolidated Guidance Memorandum, 2004, DEQ Guidance Memo: 04-2005, Legislative Rule 46CSRI. 
Tables 
Table 5. Estimated concentrations of selected congeners of polychlorinated biphenyls (PCBs) in water from the Bluestone River watershed sample set, fall 2005.

[Concentrations of PCBs are reported in $\mathrm{pg} \cdot \mathrm{L}^{-1}$ water. PCB congener numbering is follows Frame and others, 1996]

\begin{tabular}{|c|c|c|c|c|c|c|}
\hline \multirow[b]{2}{*}{ Sample name } & \multicolumn{6}{|c|}{ RARE Study Field Samples__Fall 2005} \\
\hline & Site \#1 SPMDs & Site \#2 SPMDs & Site \#3 SPMDs & Site \#4 SPMDs & Site \#5 SPMDs & Site \#6 SPMDs \\
\hline Field indentification & 9-LRR000.03 & 9-ABB000.02, Rep 1 & 9-ABB000.02, Rep 2 & 9-BST022.43 & 9-BFK000.02 & 9-BFK003.14 \\
\hline Field sample label & $\begin{array}{l}\text { Laurel Fork } \\
\text { Confluence }\end{array}$ & Abbs Valley River & Abbs Valley River & $\begin{array}{c}\text { Bluestone River } \\
\text { below Yards }\end{array}$ & Brush Fork & $\begin{array}{c}\text { Brush Fork, } \\
\text { below Armory }\end{array}$ \\
\hline \multicolumn{7}{|l|}{ PCB congener(s) } \\
\hline 001 & 3.9 & 9.5 & 2.6 & 5.0 & 15 & 7.5 \\
\hline 002 & $<1$ & $<1$ & $<1$ & $<1$ & $<1$ & $<1$ \\
\hline 004 & 4.9 & 4.2 & 3.0 & 19 & 250 & 4.6 \\
\hline 005 & 0.06 & 0.07 & 0.1 & 0.2 & 0.3 & 0.1 \\
\hline 006 & 1.4 & 0.9 & 1.0 & 3.9 & 22 & 1.3 \\
\hline 007 & $<1$ & $<1$ & $<1$ & 2.5 & 3.4 & $<1$ \\
\hline 008 & 1.6 & 0.6 & 1.2 & 9.1 & 160 & 1.5 \\
\hline 009 & 0.3 & 0.2 & 0.2 & 1.9 & 5.4 & 0.1 \\
\hline 010 & 0.8 & 1.2 & 1.1 & 1.8 & 7.9 & 0.9 \\
\hline 012,013 & 5.3 & 1.3 & 1.0 & 20 & 4.3 & 1.8 \\
\hline 015 & 1.4 & 0.04 & 0.2 & 5.7 & 73 & 1.8 \\
\hline 016 & 4.0 & 0.5 & 0.7 & 15 & 71 & 2.0 \\
\hline 017 & 7.5 & 0.8 & 0.8 & 26 & 170 & 3.5 \\
\hline 018 & 12 & 1.2 & 1.4 & 41 & 170 & 6.6 \\
\hline 019 & 3.9 & 0.4 & 0.4 & 19 & 94 & 2.4 \\
\hline 020 & 0.5 & $<1$ & $<1$ & 5.1 & 9.4 & 0.3 \\
\hline 022 & 3.4 & 0.5 & 0.4 & 9.5 & 67 & 1.5 \\
\hline 024,027 & 1.9 & $<1$ & $<1$ & 6.3 & 41 & 0.7 \\
\hline 026 & 1.6 & 0.2 & 0.1 & 6.5 & 39 & 0.9 \\
\hline 028 & 9.3 & 1.0 & 1.0 & 35 & 270 & 5.0 \\
\hline 031 & 7.1 & 4.0 & 3.5 & 49 & 200 & 4.7 \\
\hline 032 & 3.8 & 0.03 & $<1$ & 18 & 140 & 2.0 \\
\hline 033 & 8.5 & 4.4 & 3.6 & 31 & 27 & 4.3 \\
\hline 034 & $<1$ & $<1$ & $<1$ & 0.2 & 1.7 & 0.10 \\
\hline 035 & 0.9 & $<1$ & $<1$ & 1.2 & 3.8 & 0.5 \\
\hline 037,059 & 1.4 & 0.09 & 0.2 & 5.6 & 25 & 0.8 \\
\hline 040 & 2.8 & 0.2 & 0.1 & 9.4 & 35 & 1.2 \\
\hline 041 & 2.3 & 0.7 & 0.7 & 5.1 & 17 & 1.0 \\
\hline 042 & 3.7 & 0.3 & 0.2 & 12 & 46 & 1.5 \\
\hline 044 & 17 & 1.2 & 1.3 & 46 & 150 & 5.8 \\
\hline 045 & 4.2 & 1.0 & 0.8 & 12 & 49 & 1.6 \\
\hline 046 & 1.1 & $<1$ & $<1$ & 7.4 & 19 & 0.7 \\
\hline 047 & 9.9 & 2.5 & 2.4 & 46 & 68 & 4.0 \\
\hline 048 & 2.4 & 0.1 & 0.2 & 6.7 & 35 & 1.1 \\
\hline 049 & 12 & 1.7 & 1.6 & 32 & 110 & 3.9 \\
\hline 051 & 1.3 & 0.1 & 0.09 & 2.5 & 14 & 0.4 \\
\hline 052 & 37 & 18 & 17 & 94 & 160 & 14 \\
\hline 053 & 7.7 & 1.6 & 1.2 & 21 & 51 & 3.0 \\
\hline 054 & 6.6 & 5.3 & 4.9 & 15 & 4.7 & 3.0 \\
\hline 056,060 & 2.8 & 0.9 & 0.8 & 15 & 83 & 0.7 \\
\hline 064 & 7.6 & 1.0 & 0.9 & 20 & 82 & 2.9 \\
\hline 066 & 7.3 & 1.5 & 1.7 & 33 & 110 & 3.8 \\
\hline 067 & 1.1 & 0.2 & 0.4 & 1.2 & 5.2 & 0.1 \\
\hline 069 & 0.6 & 0.2 & 0.1 & 1.3 & 0.4 & 0.04 \\
\hline 070 & 14 & 2.7 & 2.4 & 36 & 85 & 5.5 \\
\hline 071 & 4.4 & 0.3 & 0.6 & 13 & 53 & 1.5 \\
\hline 073 & 0.3 & 0.1 & 0.09 & 0.9 & $<1$ & 0.1 \\
\hline 074 & 5.3 & 1.1 & 1.2 & 13 & 61 & 2.3 \\
\hline 075 & 4.9 & 1.2 & 1.1 & 56 & 19 & 5.5 \\
\hline 077 & 8.6 & 1.4 & 1.9 & 21 & 11 & 3.0 \\
\hline 081,117 & 1.7 & 0.3 & 0.3 & 2.7 & 1.8 & 0.6 \\
\hline 082 & 5.4 & 0.6 & 1.3 & 11 & 6.7 & 1.8 \\
\hline 083 & 2.6 & 0.6 & 0.6 & 6.2 & 3.0 & 0.9 \\
\hline 084 & 12 & 1.9 & 2.1 & 29 & 13 & 3.7 \\
\hline 085 & 2.3 & 1.1 & 0.7 & $<1$ & 0.5 & $<1$ \\
\hline 087 & 15 & 2.8 & 3.3 & 26 & 13 & 1.6 \\
\hline 091 & 6.8 & 1.2 & 1.4 & 14 & 7.1 & 2.1 \\
\hline 092 & 7.4 & 2.0 & 2.3 & 19 & 6.5 & 2.2 \\
\hline 095 & 30 & 5.4 & 5.7 & 79 & 26 & 9.4 \\
\hline 097 & 11 & 2.0 & 2.1 & 21 & 12 & 2.8 \\
\hline 099 & 18 & 3.9 & 4.0 & 32 & 16 & 4.4 \\
\hline 100 & $<1$ & $<1$ & $<1$ & 0.1 & 2.0 & 0.3 \\
\hline 103 & 1.3 & 2.1 & 1.8 & 3.4 & 0.6 & 0.8 \\
\hline 104 & 0.5 & 0.2 & 0.1 & 1.7 & 1.2 & 0.1 \\
\hline 105 & 10 & 2.5 & 2.7 & 17 & 9.4 & 2.4 \\
\hline 109 & 2.9 & 0.8 & 0.8 & 4.4 & 2.6 & 0.9 \\
\hline 110 & 40 & 9.4 & 9.8 & 94 & 31 & 11 \\
\hline 114 & 0.7 & 0.1 & 0.1 & 0.9 & 0.4 & 0.06 \\
\hline 115 & 1.6 & 0.4 & 0.5 & 1.5 & 1.2 & 0.6 \\
\hline 118 & 27 & 7.3 & 7.9 & 48 & 22 & 7.2 \\
\hline
\end{tabular}


Table 5. Estimated concentrations of selected congeners of polychlorinated biphenyls (PCBs) in water from the Bluestone River watershed sample set, fall 2005.-Continued

[Concentrations of PCBs are reported in $\mathrm{pg} \cdot \mathrm{L}^{-1}$ water. $\mathrm{PCB}$ congener numbering is follows Frame and others, 1996]

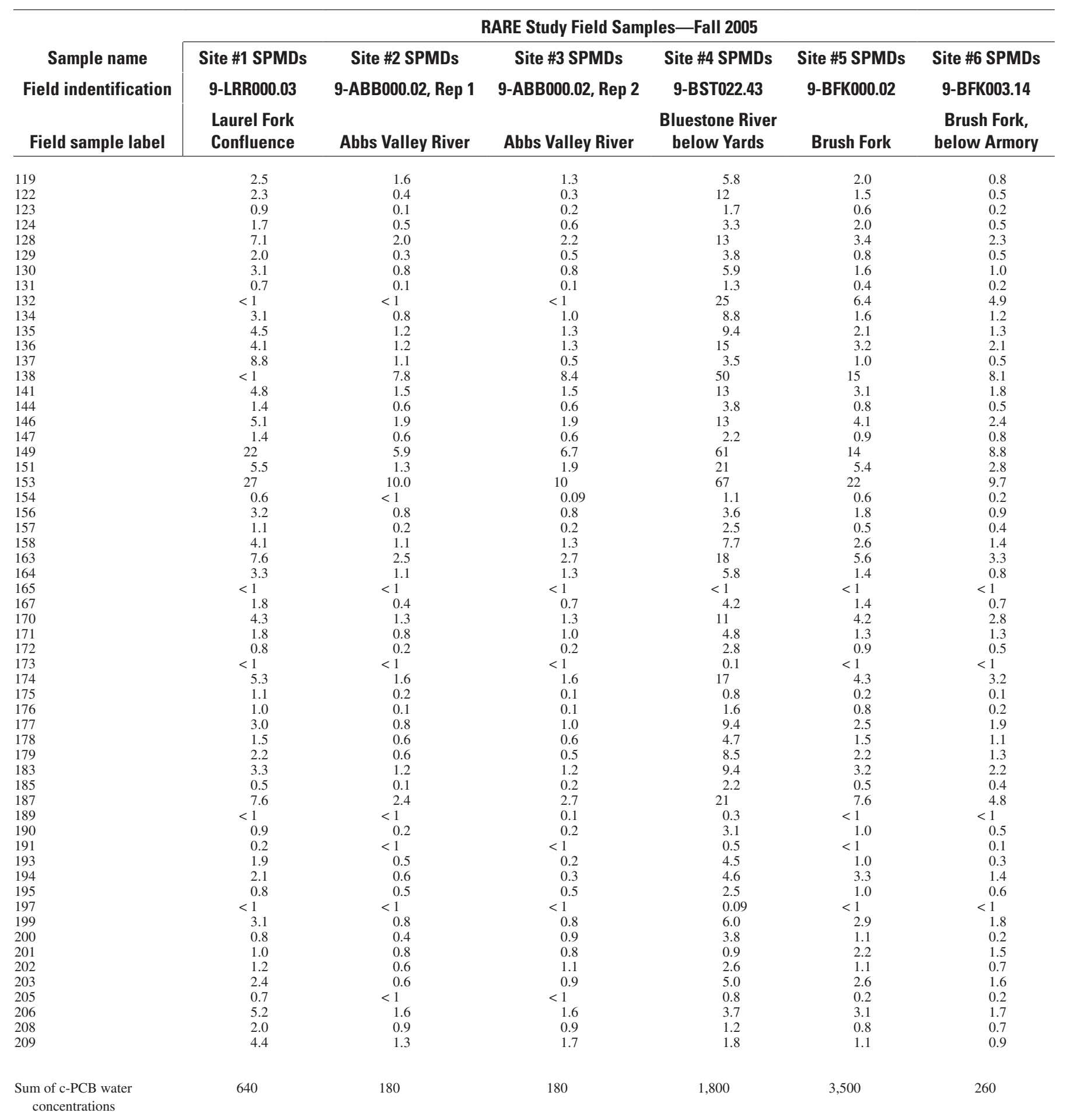


Table 5. Estimated concentrations of selected congeners of polychlorinated biphenyls (PCBs) in water from the Bluestone River watershed sample set, fall 2005.-Continued

[Concentrations of PCBs are reported in $\mathrm{pg} \cdot \mathrm{L}^{-1}$ water. PCB congener numbering is follows Frame and others, 1996]

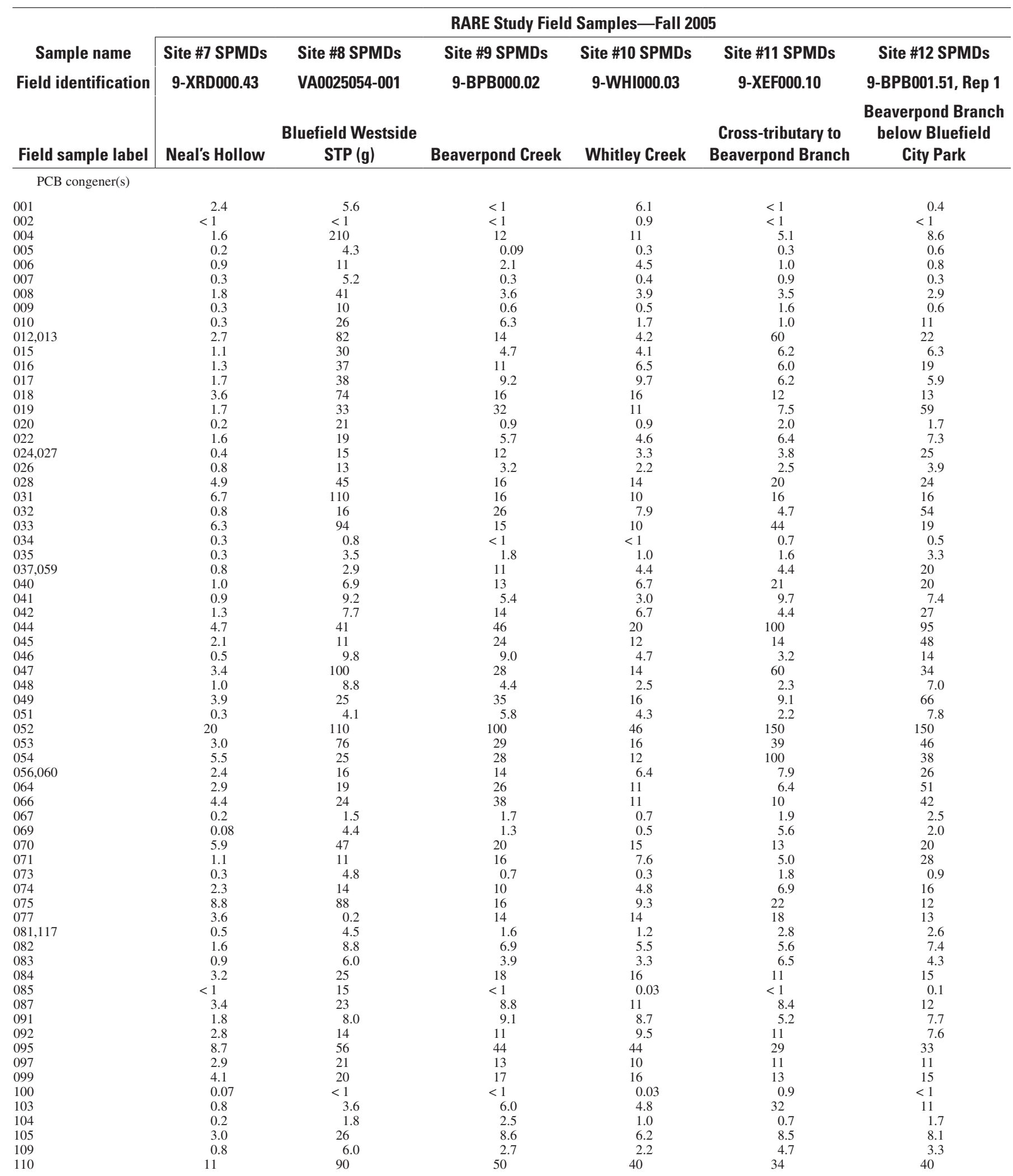


Table 5. Estimated concentrations of selected congeners of polychlorinated biphenyls (PCBs) in water from the Bluestone River watershed sample set, fall 2005. - Continued

[Concentrations of PCBs are reported in $\mathrm{pg} \cdot \mathrm{L}^{-1}$ water. $\mathrm{PCB}$ congener numbering is follows Frame and others, 1996]

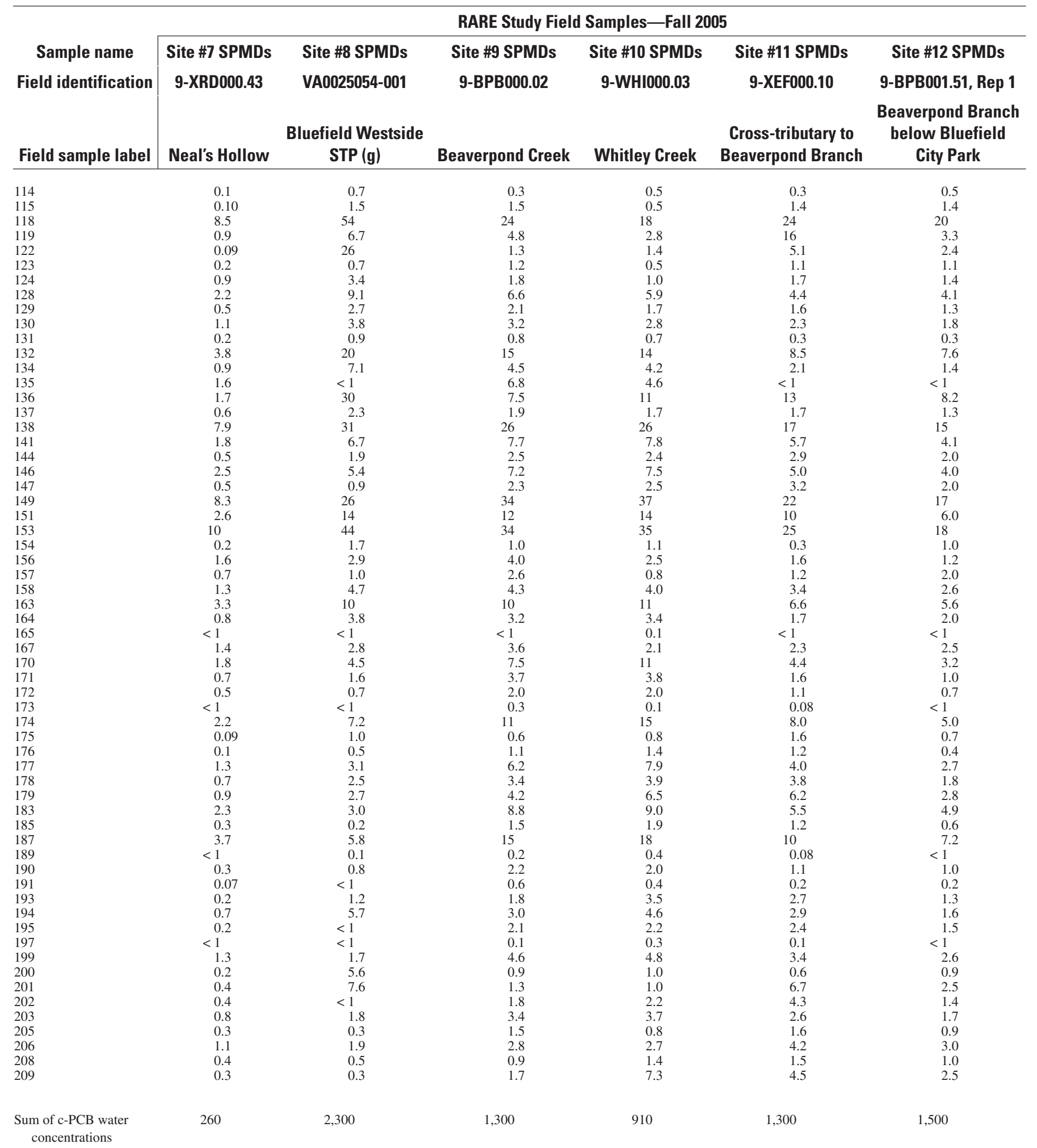


Table 5. Estimated concentrations of selected congeners of polychlorinated biphenyls (PCBs) in water from the Bluestone River watershed sample set, fall 2005.-Continued

[Concentrations of PCBs are reported in $\mathrm{pg} \cdot \mathrm{L}^{-1}$ water. PCB congener numbering is follows Frame and others, 1996]

\begin{tabular}{|c|c|c|c|c|c|}
\hline \multirow[b]{2}{*}{ Sample name } & \multicolumn{5}{|c|}{ RARE Study Field Samples_Fall 2005} \\
\hline & Site \#13 SPMDs & Site \#14 SPMDs & Site \#15 SPMDs & Site \#16 SPMDs & Site \#17 SPMDs \\
\hline Field identification & 9-BPB001.51, Rep 2 & 9-BPB000.17 & 9-BST025.23 & 9-WVC000.05 & 9-BST028.90 \\
\hline Field sample label & $\begin{array}{c}\text { Beaverpond Branch } \\
\text { below Bluefield } \\
\text { City Park }\end{array}$ & $\begin{array}{l}\text { Beaverpond Branch } \\
\text { at resurgence (h) }\end{array}$ & 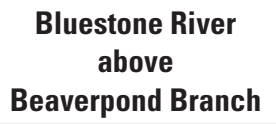 & $\begin{array}{l}\text { Wright Valley } \\
\text { Creek }\end{array}$ & $\begin{array}{l}\text { Bluestone River below } \\
\text { water treatment plant }\end{array}$ \\
\hline \multicolumn{6}{|l|}{ PCB congener(s) } \\
\hline 001 & 0.8 & $<1$ & 0.9 & $<1$ & $<1$ \\
\hline 002 & $<1$ & $<1$ & $<1$ & $<1$ & $<1$ \\
\hline 004 & 10 & 41 & 9.3 & 1.9 & 0.5 \\
\hline 005 & 0.2 & 1.2 & 0.10 & 0.08 & 0.08 \\
\hline 006 & 1.0 & 3.1 & $\begin{array}{l}1.0 \\
\text { l. }\end{array}$ & 0.3 & 0.6 \\
\hline 007 & 0.3 & 0.2 & 0.09 & $<1$ & $<1$ \\
\hline 008 & 3.0 & 8.9 & 3.9 & 0.9 & 0.2 \\
\hline 009 & 0.7 & 0.7 & 0.4 & 0.4 & 0.08 \\
\hline 010 & 12 & 150 & 0.7 & 0.2 & 0.2 \\
\hline 012,013 & 24 & 6.6 & 2.3 & 1.4 & 1.4 \\
\hline 015 & 7.6 & 35 & 5.9 & 0.5 & 0.2 \\
\hline 016 & 23 & 340 & 4.3 & 0.8 & 0.6 \\
\hline 017 & 6.6 & 23 & 24 & 1.6 & 0.8 \\
\hline 018 & 15 & 58 & 10 & 2.1 & 1.2 \\
\hline 019 & 71 & 820 & 9.3 & 1.1 & 0.5 \\
\hline 020 & 2.1 & 16 & 0.4 & 0.06 & 0.05 \\
\hline 022 & 9.0 & 73 & 2.4 & 0.6 & 0.4 \\
\hline 024,027 & 31 & 360 & 4.0 & 0.3 & 0.1 \\
\hline 026 & 4.6 & 24 & 1.4 & 0.3 & 0.1 \\
\hline 028 & 28 & 120 & 11 & 2.0 & 1.3 \\
\hline 031 & 21 & 110 & 11 & 1.6 & 2.7 \\
\hline 032 & 68 & 1,200 & 10 & 0.7 & 0.2 \\
\hline 033 & 21 & 9.9 & 4.7 & 1.5 & 2.4 \\
\hline 034 & 0.6 & 6.5 & 0.05 & $<1$ & $<1$ \\
\hline 035 & 4.4 & 63 & 1.4 & 0.06 & $<1$ \\
\hline 037,059 & 24 & 250 & 1.3 & 0.4 & 0.2 \\
\hline 040 & 28 & 280 & 2.3 & 0.6 & 0.3 \\
\hline 041 & 9.0 & 49 & 1.4 & 0.5 & 0.4 \\
\hline 042 & 33 & 380 & 5.5 & 0.7 & 0.4 \\
\hline 044 & 110 & 1,300 & 20 & 2.8 & 1.6 \\
\hline 045 & 56 & 570 & 3.3 & 1.0 & 0.5 \\
\hline 046 & 16 & 170 & 2.8 & 0.3 & $<1$ \\
\hline 047 & 43 & 330 & 30 & 3.8 & 3.6 \\
\hline 048 & 8.4 & 77 & 1.8 & 0.3 & 0.2 \\
\hline 049 & 85 & 940 & 23 & 2.2 & 1.4 \\
\hline 051 & 9.7 & 120 & 8.4 & 0.6 & 0.3 \\
\hline 052 & 190 & 1,400 & 38 & 7.8 & 5.9 \\
\hline 053 & 56 & 500 & 19 & 1.8 & 1.6 \\
\hline 054 & 47 & 25 & 4.8 & 2.2 & 2.4 \\
\hline 056,060 & 31 & 320 & 4.0 & 0.3 & 0.6 \\
\hline 064 & 65 & 700 & 6.9 & 1.6 & 1.0 \\
\hline 066 & 49 & 470 & 12 & 1.8 & 1.6 \\
\hline 067 & 2.8 & 9.5 & 0.7 & $<1$ & $<1$ \\
\hline 069 & 2.4 & 4.7 & 0.3 & 0.1 & 0.08 \\
\hline 070 & 23 & 120 & 18 & 3.0 & 2.3 \\
\hline 071 & 35 & 430 & 7.9 & 0.7 & 0.2 \\
\hline 073 & 1.1 & 4.7 & 0.6 & 0.07 & 0.05 \\
\hline 074 & 19 & 170 & 5.9 & 1.1 & 1.0 \\
\hline 075 & 14 & 30 & 17 & 2.4 & 15 \\
\hline 077 & 13 & 52 & 14 & 3.7 & 2.0 \\
\hline 081,117 & 2.8 & 8.4 & 2.4 & 0.5 & 0.4 \\
\hline 082 & 8.1 & 43 & 5.1 & 1.3 & 0.8 \\
\hline 083 & $\begin{array}{l}0.1 \\
4.5\end{array}$ & 18 & 3.1 & 0.7 & 0.5 \\
\hline 084 & 17 & 120 & 12 & 2.6 & 1.3 \\
\hline 085 & 0.8 & 20 & $<1$ & $<1$ & $<1$ \\
\hline 087 & 11 & 89 & 15 & 3.0 & 1.8 \\
\hline 091 & 8.3 & 53 & 7.8 & 1.7 & 0.9 \\
\hline 092 & 10.0 & 38 & 9.3 & 2.3 & 1.3 \\
\hline 095 & 38 & 210 & 30 & 8.1 & 3.6 \\
\hline 097 & 12 & 74 & 12 & 2.3 & 1.4 \\
\hline 099 & 16 & 92 & 19 & 3.2 & 2.2 \\
\hline 100 & $<1$ & 16 & 0.5 & 0.3 & 0.2 \\
\hline 103 & 13 & 15 & 2.5 & 1.4 & 1.5 \\
\hline 104 & 1.9 & 4.5 & 0.5 & 0.1 & 0.02 \\
\hline 105 & 8.7 & 39 & 11 & 1.9 & 1.4 \\
\hline 109 & 3.8 & 8.1 & 2.9 & 0.6 & 0.6 \\
\hline 110 & 43 & 200 & 43 & 8.8 & 5.0 \\
\hline 114 & 0.4 & 2.6 & 0.5 & 0.09 & 0.09 \\
\hline 115 & 1.9 & 3.2 & 1.2 & 0.08 & 0.09 \\
\hline
\end{tabular}


Table 5. Estimated concentrations of selected congeners of polychlorinated biphenyls (PCBs) in water from the Bluestone River watershed sample set, fall 2005. - Continued

[Concentrations of PCBs are reported in pg. $\mathrm{L}^{-1}$ water. $\mathrm{PCB}$ congener numbering is follows Frame and others, 1996]

\begin{tabular}{|c|c|c|c|c|c|}
\hline \multirow[b]{2}{*}{ Sample name } & \multicolumn{5}{|c|}{ RARE Study Field Samples_Fall 2005} \\
\hline & Site \#13 SPMDs & Site \#14 SPMDs & Site \#15 SPMDs & Site \#16 SPMDs & Site \#17 SPMDs \\
\hline Field identification & 9-BPB001.51, Rep 2 & 9-BPB000.17 & 9-BST025.23 & 9-WVC000.05 & 9-BST028.90 \\
\hline Field sample label & $\begin{array}{c}\text { Beaverpond Branch } \\
\text { below Bluefield } \\
\text { City Park }\end{array}$ & $\begin{array}{l}\text { Beaverpond Branch } \\
\text { at resurgence }(\mathrm{h})\end{array}$ & $\begin{array}{l}\text { Bluestone River } \\
\text { above } \\
\text { Beaverpond Branch }\end{array}$ & $\begin{array}{l}\text { Wright Valley } \\
\text { Creek }\end{array}$ & $\begin{array}{l}\text { Bluestone River below } \\
\text { water treatment plant }\end{array}$ \\
\hline 118 & 22 & 86 & 33 & 5.8 & 4.3 \\
\hline 119 & 8.7 & 21 & 2.5 & 0.7 & 0.8 \\
\hline 122 & 2.1 & 3.6 & 0.8 & 0.2 & 0.5 \\
\hline 123 & 1.3 & 2.6 & 0.5 & 0.2 & 0.1 \\
\hline 124 & 1.5 & 6.0 & 2.0 & 0.4 & 0.2 \\
\hline 128 & 4.3 & 4.9 & 6.1 & 1.7 & 1.0 \\
\hline 129 & 1.3 & 1.3 & 1.9 & 0.5 & 0.2 \\
\hline 130 & 1.9 & 2.0 & 2.6 & 1.0 & 0.4 \\
\hline 131 & 0.4 & 0.6 & 0.6 & 0.2 & 0.08 \\
\hline 132 & 7.7 & 10 & 10 & 3.5 & 2.3 \\
\hline 134 & 1.7 & 2.5 & 3.1 & 1.2 & 0.6 \\
\hline 135 & 0.4 & 9.1 & 4.3 & 2.8 & 0.5 \\
\hline 136 & 6.4 & 4.8 & 4.7 & 2.8 & 1.1 \\
\hline 137 & 1.5 & 1.8 & 2.0 & 0.6 & 0.2 \\
\hline 138 & 15 & 17 & 24 & 9.6 & 4.2 \\
\hline 141 & 4.3 & 4.4 & 5.4 & 3.1 & 0.9 \\
\hline 144 & 1.8 & 1.9 & 1.3 & 0.8 & 0.3 \\
\hline 146 & 4.1 & 4.6 & 5.5 & 3.6 & 1.3 \\
\hline 147 & 2.3 & 3.1 & 1.7 & 0.7 & 0.4 \\
\hline 149 & 17 & $21^{3.1}$ & 23 & 16 & 4.4 \\
\hline 151 & 6.4 & 6.7 & 7.7 & 7.0 & 1.7 \\
\hline 153 & 20 & 22 & 28 & 17 & 5.7 \\
\hline 154 & 1.0 & 1.1 & 0.5 & 0.2 & 0.1 \\
\hline 156 & 2.3 & 1.9 & 3.6 & 0.8 & 0.4 \\
\hline 157 & 2.0 & 0.6 & 1.3 & 0.2 & 0.1 \\
\hline 158 & 2.6 & 2.9 & 4.2 & 1.4 & 0.6 \\
\hline 163 & 5.6 & 5.9 & 8.8 & 5.2 & 1.8 \\
\hline 164 & 2.0 & 2.2 & 2.8 & 1.6 & 0.5 \\
\hline 165 & $<1$ & $<1$ & $<1$ & $<1$ & $<1$ \\
\hline 167 & 2.5 & 1.6 & 2.1 & 0.6 & 0.3 \\
\hline 170 & 3.3 & 1.9 & 5.8 & 5.4 & 1.1 \\
\hline 171 & 1.0 & 0.8 & 2.4 & 2.3 & 0.5 \\
\hline 172 & 0.8 & 0.4 & 0.7 & 1.6 & 0.2 \\
\hline 173 & $<1$ & $<1$ & 0.07 & 0.1 & $<1$ \\
\hline 174 & 4.9 & 2.5 & 7.1 & 8.9 & 1.6 \\
\hline 175 & 0.7 & 1.5 & 0.3 & 0.5 & $<1$ \\
\hline 176 & 0.3 & 0.1 & 0.6 & 1.0 & 0.1 \\
\hline 177 & 2.6 & 1.5 & 4.5 & 5.4 & 1.1 \\
\hline 178 & 1.7 & 1.1 & 2.4 & 3.3 & 0.7 \\
\hline 179 & 2.6 & 1.6 & 3.6 & 5.1 & 0.9 \\
\hline 183 & 3.8 & 3.6 & 5.0 & 5.0 & 1.3 \\
\hline 185 & 0.6 & 0.3 & 0.9 & 1.3 & 0.1 \\
\hline 187 & 6.8 & 3.5 & 11 & 14 & 2.8 \\
\hline 189 & $<1$ & $<1$ & 0.1 & 0.1 & $<1$ \\
\hline 190 & 0.7 & 0.4 & 1.4 & 1.6 & 0.3 \\
\hline 191 & 0.4 & 1.3 & 0.4 & 0.3 & $<1$ \\
\hline 193 & 1.7 & 1.0 & 1.5 & 1.7 & 0.4 \\
\hline 194 & 1.6 & 0.5 & 2.6 & 2.8 & 0.7 \\
\hline 195 & 1.7 & 0.6 & 1.1 & 1.4 & 0.4 \\
\hline 197 & $<1$ & $<1$ & 0.09 & 0.1 & $<1$ \\
\hline 199 & 2.4 & 1.3 & 3.2 & 3.8 & 0.9 \\
\hline 200 & 0.5 & 0.3 & 0.2 & 0.4 & 0.06 \\
\hline 201 & 3.0 & 7.3 & 1.1 & 1.0 & 0.8 \\
\hline 202 & 1.7 & 1.7 & 1.2 & 1.6 & 0.4 \\
\hline 203 & 1.6 & 0.9 & 2.6 & 3.1 & 0.6 \\
\hline 205 & 1.1 & 1.5 & 0.6 & 0.7 & 0.1 \\
\hline 206 & 2.9 & 1.9 & 2.0 & 1.7 & 0.8 \\
\hline 208 & 0.9 & 0.7 & 0.7 & 0.5 & 0.2 \\
\hline 209 & 3.1 & 1.0 & 0.3 & 0.3 & $<1$ \\
\hline $\begin{array}{l}\text { Sum of c-PCB water } \\
\text { concentrations }\end{array}$ & 1,700 & 13,000 & 800 & 260 & 130 \\
\hline
\end{tabular}


Table 5. Estimated concentrations of selected congeners of polychlorinated biphenyls (PCBs) in water from the Bluestone River watershed sample set, fall 2005.-Continued

[Concentrations of PCBs are reported in $\mathrm{pg} \cdot \mathrm{L}^{-1}$ water. $\mathrm{PCB}$ congener numbering is follows Frame and others, 1996]

\begin{tabular}{|c|c|c|c|}
\hline \multirow[b]{2}{*}{ Sample name } & \multicolumn{3}{|c|}{ WVDEP Study Field Samples_-Fall 2005} \\
\hline & Site \#1 SPMDs & Site \#2 SPMDs & Site \#3 SPMDs (*) \\
\hline Field identification & WVDEP-1 & WVDEP-2 & WVDEP-3 \\
\hline Field sample label & Beacon Cave \#1 (h) & Beacon Cave \#2 (h) & Morris Spring \\
\hline \multicolumn{4}{|l|}{ PCB congener(s) } \\
\hline 001 & 0.4 & 0.8 & $<1$ \\
\hline 002 & $<1$ & $<1$ & $<1$ \\
\hline 004 & 72 & 47 & 0.5 \\
\hline 005 & 0.8 & 0.2 & 0.1 \\
\hline 006 & 5.3 & 2.9 & 0.4 \\
\hline 007 & 0.7 & 0.3 & 0.6 \\
\hline 008 & 13 & 7.0 & $<1$ \\
\hline 009 & 1.4 & 0.7 & 0.4 \\
\hline 010 & 240 & 160 & 0.2 \\
\hline 012,013 & 6.4 & 4.8 & 5.5 \\
\hline 015 & 44 & 29 & 1.6 \\
\hline 016 & 490 & 330 & 1.1 \\
\hline 017 & 41 & 22 & $<1$ \\
\hline 018 & 80 & 49 & 0.6 \\
\hline 019 & 1,200 & 790 & 1.3 \\
\hline 020 & 29 & 15 & 0.1 \\
\hline 022 & 110 & 64 & 0.3 \\
\hline 024,027 & 530 & 320 & 0.5 \\
\hline 026 & 36 & 20 & 0.04 \\
\hline 028 & 160 & 98 & 1.3 \\
\hline 031 & 110 & 55 & 24 \\
\hline 032 & 2,000 & 1,200 & 0.8 \\
\hline 033 & 12 & 8.2 & 12 \\
\hline 034 & 12 & 6.3 & 0.1 \\
\hline 035 & 110 & 66 & 2.6 \\
\hline 037,059 & 340 & 200 & 1.2 \\
\hline 040 & 390 & 230 & 1.1 \\
\hline 041 & 75 & 42 & 2.1 \\
\hline 042 & 540 & 310 & 1.0 \\
\hline 044 & 1,600 & 990 & 1.5 \\
\hline 045 & 770 & 470 & 4.0 \\
\hline 046 & 230 & 140 & 2.2 \\
\hline 047 & 440 & 240 & 8.2 \\
\hline 048 & 120 & 63 & $<1$ \\
\hline 049 & 1,300 & 740 & 1.6 \\
\hline 051 & 190 & 110 & 0.8 \\
\hline 052 & 1,600 & 1,000 & 60 \\
\hline 053 & 690 & 430 & 9.2 \\
\hline 054 & 31 & 27 & 21 \\
\hline 056,060 & 440 & 260 & 0.8 \\
\hline 064 & 930 & 550 & 1.4 \\
\hline 066 & 630 & 360 & 1.4 \\
\hline 067 & 18 & 9.9 & 0.4 \\
\hline 069 & 6.3 & 3.7 & 0.2 \\
\hline 070 & 120 & 72 & 0.5 \\
\hline 071 & 620 & 360 & 1.7 \\
\hline 073 & 5.3 & 3.5 & 0.5 \\
\hline 074 & 210 & 130 & 0.2 \\
\hline 075 & 39 & 22 & 1.5 \\
\hline 077 & 53 & 32 & 4.1 \\
\hline 081,117 & 8.4 & 5.8 & 0.3 \\
\hline 082 & 53 & 33 & 1.7 \\
\hline 083 & 22 & 14 & 1.8 \\
\hline 084 & 150 & 92 & 7.4 \\
\hline 085 & 26 & 19 & $<1$ \\
\hline 087 & 110 & 65 & 1.9 \\
\hline 091 & 64 & 40 & 3.8 \\
\hline 092 & 41 & 27 & 2.0 \\
\hline 095 & 260 & 160 & 18 \\
\hline 097 & 90 & 55 & 2.0 \\
\hline 099 & 99 & 62 & 5.3 \\
\hline 100 & 17 & 11 & 0.04 \\
\hline 103 & 13 & 9.8 & 4.4 \\
\hline 104 & 1.1 & 1.8 & 0.6 \\
\hline 105 & 43 & 28 & 1.1 \\
\hline 109 & 8.6 & 5.7 & 1.6 \\
\hline 110 & 230 & 140 & 13 \\
\hline 114 & 2.0 & 1.4 & 0.1 \\
\hline 115 & 7.8 & 2.2 & 0.6 \\
\hline
\end{tabular}


Table 5. Estimated concentrations of selected congeners of polychlorinated biphenyls (PCBs) in water from the Bluestone River watershed sample set, fall 2005.-Continued

[Concentrations of PCBs are reported in $\mathrm{pg} \cdot \mathrm{L}^{-1}$ water. $\mathrm{PCB}$ congener numbering is follows Frame and others, 1996]

\begin{tabular}{|c|c|c|c|}
\hline \multirow{4}{*}{$\begin{array}{c}\text { Sample name } \\
\text { Field identification } \\
\text { Field sample label }\end{array}$} & \multicolumn{3}{|c|}{ WVDEP Study Field Samples_Fall 2005} \\
\hline & Site \#1 SPMDs & Site \#2 SPMDs & Site \#3 SPMDs (*) \\
\hline & WVDEP-1 & WVDEP-2 & WVDEP-3 \\
\hline & Beacon Cave \#1 (h) & Beacon Cave \#2 (h) & Morris Spring \\
\hline 118 & 83 & 57 & 3.0 \\
\hline 119 & 22 & 16 & 5.5 \\
\hline 122 & 4.1 & 2.6 & 0.4 \\
\hline 123 & 3.4 & 2.2 & 0.4 \\
\hline 124 & 6.2 & 3.9 & 0.4 \\
\hline 128 & 3.3 & 2.6 & 2.5 \\
\hline 129 & 1.1 & 0.7 & 0.7 \\
\hline 130 & 1.6 & 1.1 & 1.4 \\
\hline 131 & 0.5 & 0.3 & 0.3 \\
\hline 132 & 8.9 & 7.4 & 6.1 \\
\hline 134 & 2.1 & 1.6 & 1.4 \\
\hline 135 & 6.0 & 4.8 & $<1$ \\
\hline 136 & 5.0 & 4.2 & 5.6 \\
\hline 137 & 1.4 & 0.9 & 0.7 \\
\hline 138 & 12 & 8.9 & 5.9 \\
\hline 141 & 3.3 & 2.6 & 1.7 \\
\hline 144 & 1.0 & 0.8 & 1.0 \\
\hline 146 & 3.2 & 2.6 & 2.0 \\
\hline 147 & 2.4 & 1.4 & 1.0 \\
\hline 149 & 16 & 11 & 13 \\
\hline 151 & 5.9 & 4.1 & 4.0 \\
\hline 153 & 18 & 13 & 6.8 \\
\hline 154 & 1.3 & 0.9 & 0.2 \\
\hline 156 & 1.2 & 1.2 & 0.7 \\
\hline 157 & 0.3 & 0.4 & 0.7 \\
\hline 158 & 2.2 & 1.7 & 1.1 \\
\hline 163 & 4.3 & 3.2 & 2.9 \\
\hline 164 & 1.7 & 1.2 & 1.5 \\
\hline 165 & $<1$ & $<1$ & $<1$ \\
\hline 167 & 0.9 & 0.8 & 1.0 \\
\hline 170 & 1.1 & 0.8 & 2.3 \\
\hline 171 & 0.5 & 0.4 & 0.9 \\
\hline 172 & 0.2 & 0.2 & 0.6 \\
\hline 173 & $<1$ & $<1$ & 0.04 \\
\hline 174 & 1.8 & 1.3 & 3.4 \\
\hline 175 & 0.5 & 0.6 & 0.3 \\
\hline 176 & 0.1 & 0.09 & 0.3 \\
\hline 177 & 1.1 & 0.7 & 1.9 \\
\hline 178 & 0.8 & 0.6 & 1.1 \\
\hline 179 & 1.4 & 0.7 & 1.7 \\
\hline 183 & 2.5 & 1.2 & 2.4 \\
\hline 185 & 0.2 & 0.1 & 0.4 \\
\hline 187 & 2.8 & 2.1 & 4.3 \\
\hline 189 & $<1$ & $<1$ & $<1$ \\
\hline 190 & 0.2 & 0.2 & 0.5 \\
\hline 191 & $<1$ & $<1$ & 0.1 \\
\hline 193 & 0.7 & 0.2 & 0.5 \\
\hline 194 & 0.5 & 0.3 & 0.9 \\
\hline 195 & 0.5 & 0.3 & 0.9 \\
\hline 197 & $<1$ & $<1$ & $<1$ \\
\hline 199 & 0.7 & 0.6 & 1.2 \\
\hline 200 & 0.4 & 0.1 & 0.2 \\
\hline 201 & 3.3 & 2.9 & 0.7 \\
\hline 202 & 0.7 & 0.4 & 0.4 \\
\hline 203 & 0.5 & 0.3 & 0.8 \\
\hline 205 & 1.6 & 1.4 & 0.4 \\
\hline 206 & 0.3 & 0.3 & 0.8 \\
\hline 208 & $<1$ & $<1$ & 0.1 \\
\hline 209 & $<1$ & $<1$ & $<1$ \\
\hline $\begin{array}{c}\text { Sum of c-PCB water } \\
\text { concentrations }\end{array}$ & 18,000 & 11,000 & 350 \\
\hline
\end{tabular}




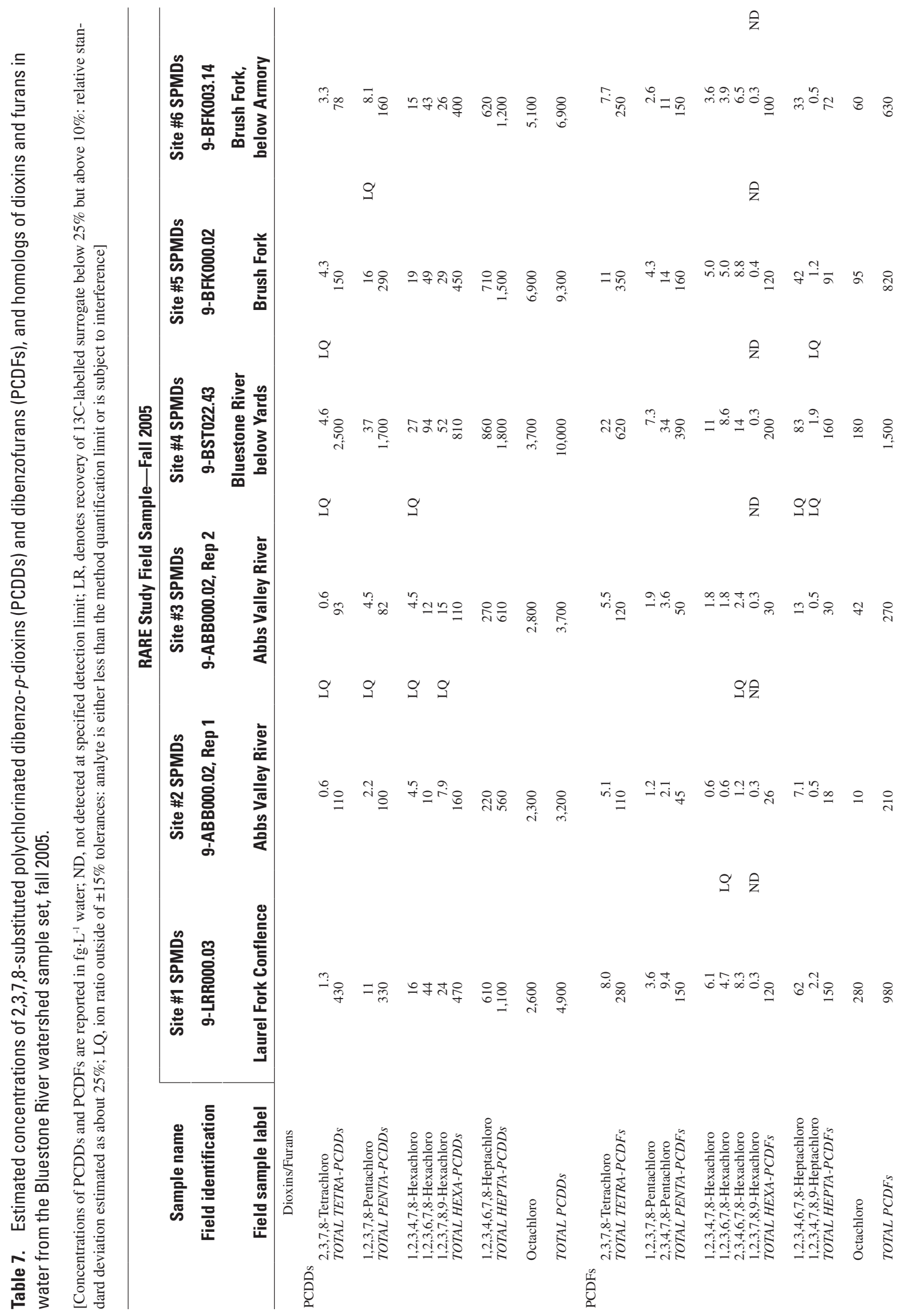




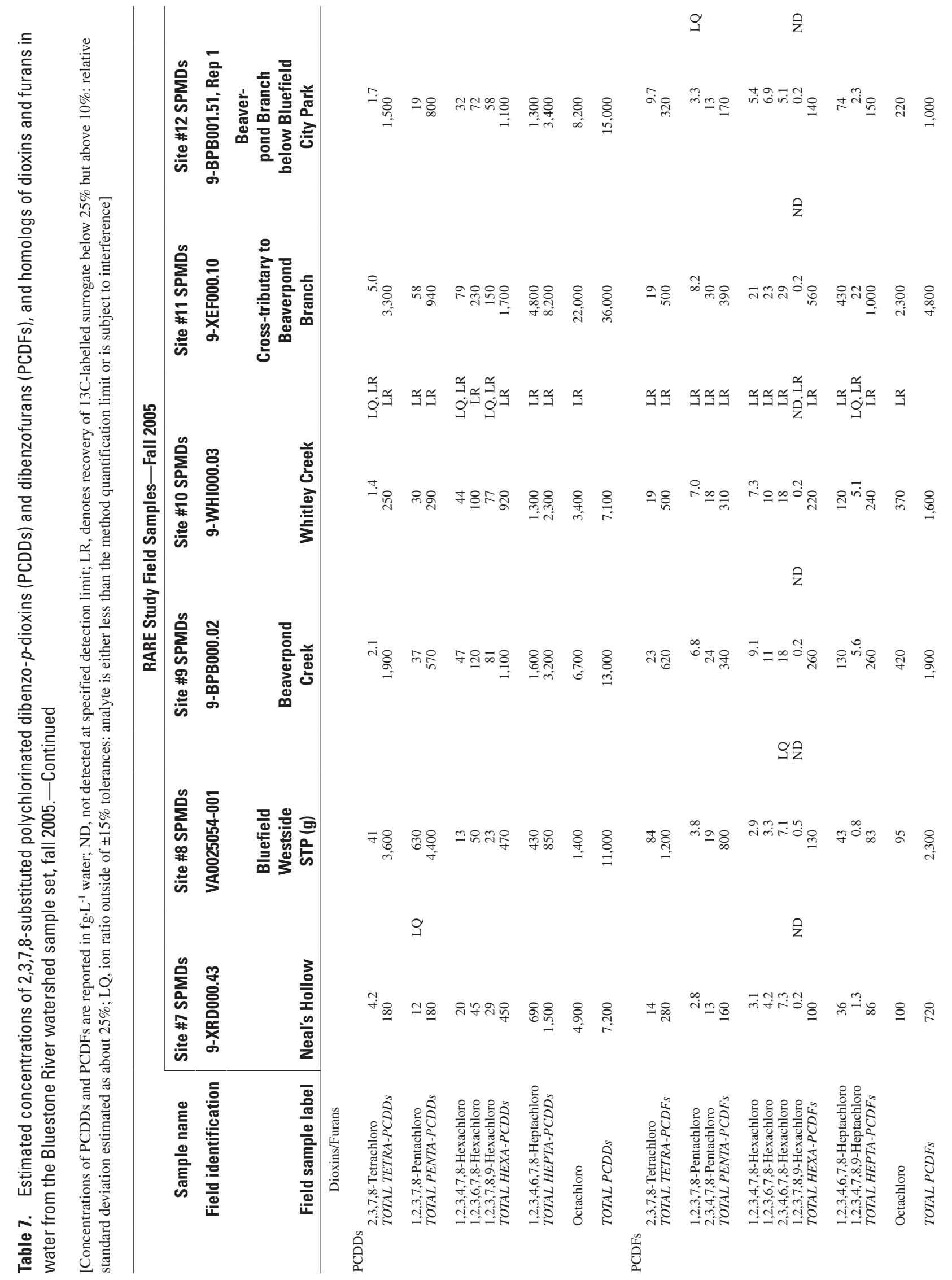




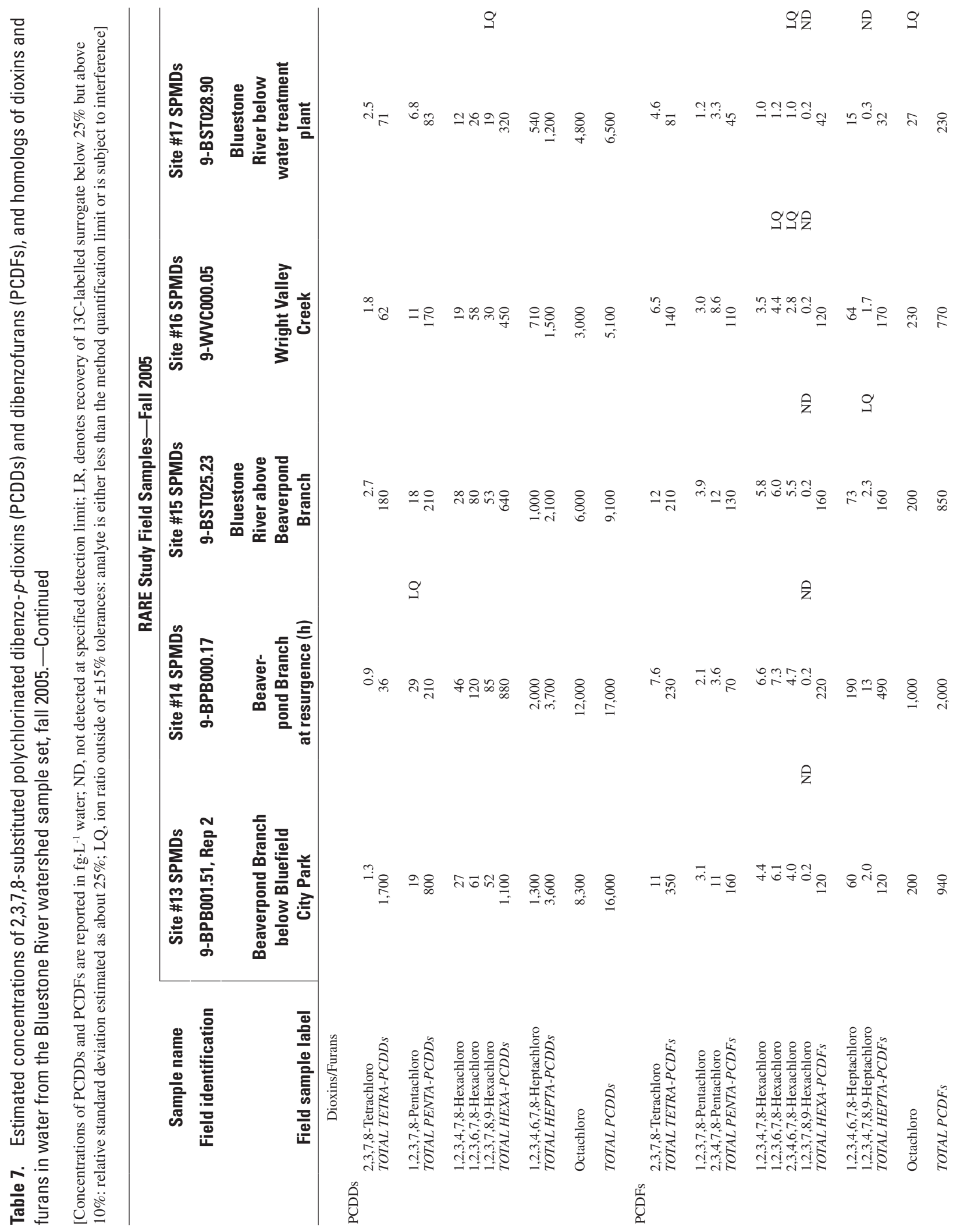




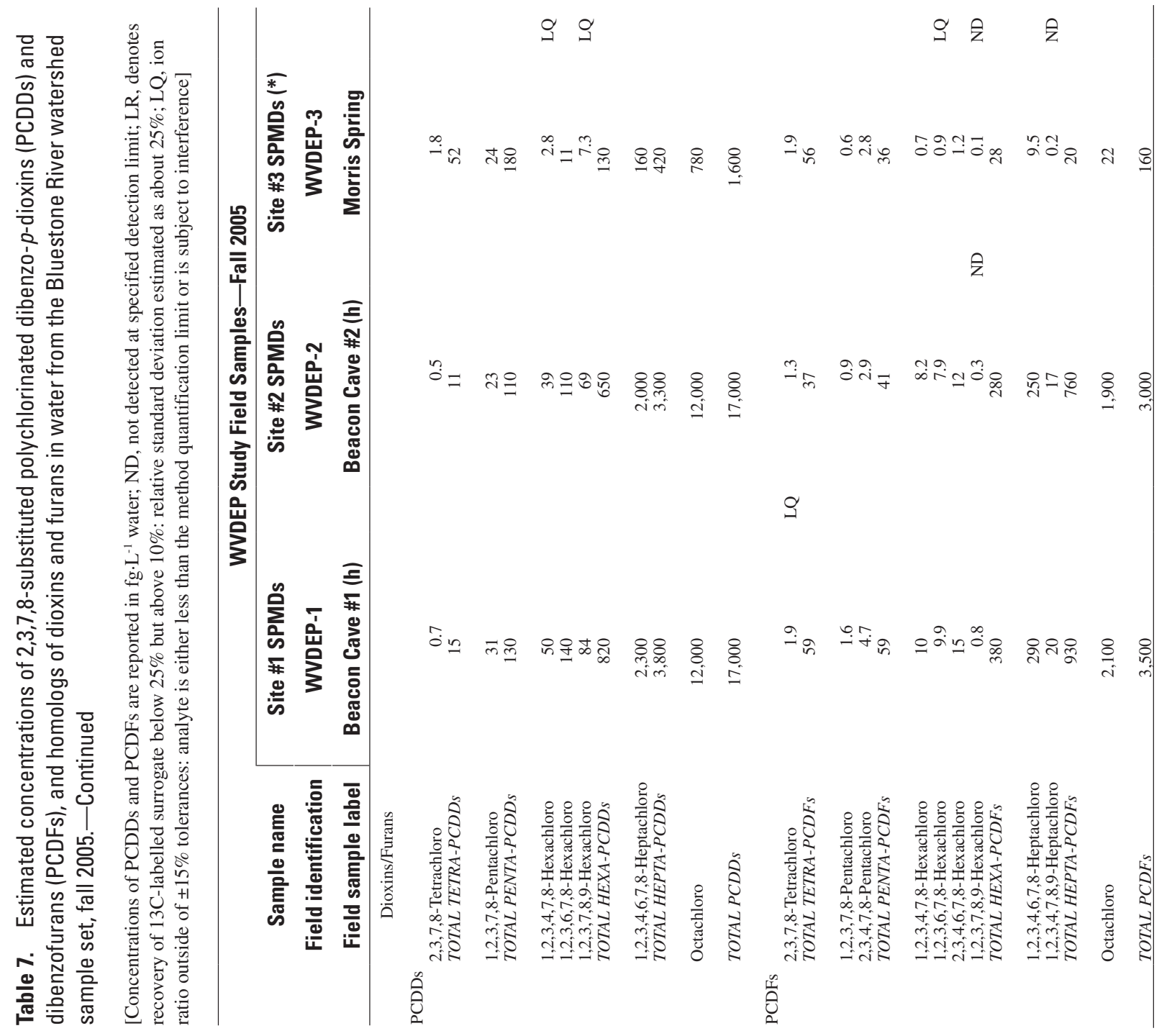




\section{Prepared by:}

USGS Enterprise Publishing Network

Rolla Publishing Service Center

1400 Independence Road

Rolla, M0 65401

For more information concerning this publication, contact:

Director

U.S. Geological Survey

Columbia Environmental Research Center

4200 New Haven Road

Columbia, M0 65201

(573) 875-5399

Or visit the Columbia Environmental Research Center website at: http://www.cerc.usgs.gov 



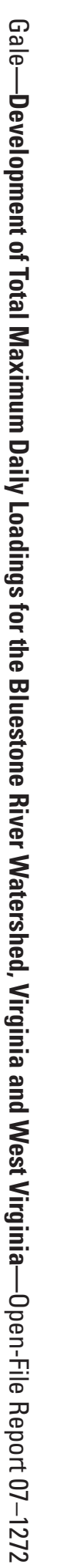

8 Printed on recycled paper 